NBER WORKING PAPER SERIES

SEGREGATION AND TIEBOUT SORTING:

INVESTIGATING THE LINK BETWEEN INVESTMENTS IN PUBLIC GOODS AND NEIGHBORHOOD TIPPING

\author{
H. Spencer Banzhaf \\ Randall P. Walsh \\ Working Paper 16057 \\ http://www.nber.org/papers/w16057 \\ NATIONAL BUREAU OF ECONOMIC RESEARCH \\ 1050 Massachusetts Avenue \\ Cambridge, MA 02138 \\ June 2010
}

Support for this research was provided by the National Science Foundation, NSF SES-03-21566. Additional support for Banzhaf was provided by the Property and Environment Research Center (PERC). We thank partici-pants in a 2008 ASSA Session, the 2009 NBER Summer Institute, and in seminars at Arizona State, Brown, Cornell, Duke, Georgetown, Harvard, PERC, Resources for the Future, the University of British Columbia, the University of Georgia, the University of Kentucky, the University of Wyoming, and Yale for comments on earlier versions of this paper. We especially thank Patrick Bayer, Antonio Bento, Don Fullerton, and Kerry Smith for their extensive comments. The views expressed herein are those of the authors and do not necessarily reflect the views of the National Bureau of Economic Research.

NBER working papers are circulated for discussion and comment purposes. They have not been peerreviewed or been subject to the review by the NBER Board of Directors that accompanies official NBER publications.

(C) 2010 by H. Spencer Banzhaf and Randall P. Walsh. All rights reserved. Short sections of text, not to exceed two paragraphs, may be quoted without explicit permission provided that full credit, including (C) notice, is given to the source. 
Segregation and Tiebout Sorting: Investigating the Link between Investments in Public Goods and Neighborhood Tipping

H. Spencer Banzhaf and Randall P. Walsh

NBER Working Paper No. 16057

June 2010

JEL No. H4,J1,Q5,R2

\title{
ABSTRACT
}

Segregation has been a recurring social concern throughout human history. While much progress has been made to our understanding of the mechanisms driving segregation, work to date has ignored the role played by location-specific amenities. Nonetheless, policy remedies for reducing group inequity often involve place-based investments in minority communities. In this paper, we introduce an exogenous location-specific public good into a model of group segregation. We characterize the equilibria of the model and derive the comparative statics of improvements to the local public goods. We show that the dynamics of neighborhood tipping depend on the levels of public goods. We also show that investments in low-public good communities can actually increase segregation.

\author{
H. Spencer Banzhaf \\ Department of Economics \\ Andrew Young School of Policy Studies \\ Georgia State University \\ P.O. Box 3992 \\ Atlanta, GA 30302 \\ and NBER \\ hsbanzhaf@gsu.edu \\ Randall P. Walsh \\ Department of Economics \\ University of Pittsburgh \\ 4901 WW Posvar Hall \\ 230 S. Bouquet St. \\ Pittsburgh, PA 15260 \\ and NBER \\ walshr@pitt.edu
}




\title{
Segregation and Tiebout Sorting:
}

\section{Investigating the Link between Investments in Public Goods and Neighborhood Tipping}

\begin{abstract}
In the white community, the path to a more perfect union means acknowledging that what ails the African-American community does not just exist in the minds of black people; that the legacy of discrimination - and current incidents of discrimination, while less overt than in the past - are real and must be addressed. Not just with words, but with deeds - by investing in our schools and our communities....
\end{abstract}

-Barack Obama

\section{Introduction}

Racial segregation of one form or another has been a recurring social concern throughout human history. In the United States, much has changed since Brown vs. Board of Education of Topeka and the Civil Rights Act of 1964 ended de jure racial segregation. But despite the improvements in black educational achievement, the narrowing of black-white income gaps, and even the election of the first African-American President, de facto racial segregation continues to be one of the country's most prevalent social issues.

Addressing this important topic, economists have explored the social mechanisms driving segregation. Schelling $(1969,1971)$ and Pancs and Vriend (2007) have shown that the dynamics of neighborhood "tipping" can force segregated outcomes even when there are tastes for some degree of integration. More recently, Card, Mas, and Rothstein (2008) have shown that, empirically, white households flee neighborhoods once they become 5-20\% minority. Consistent with this phenomenon, Cutler, Glaeser, and Vigdor (1999) and Kiel and Zabel (1996) find that white communities do command a price premium in part precisely because of their whiteness. In related work, Hoff and Sen (2005) and Sethi and Somanathan (2004) show how positive externalities from the activities of richer households can impact community composition. At the same time, Bayer, Fang, and McMillan (2005) and Sethi and Somanathan (2004) show that reducing income inequality between groups can actually increase group segregation, because richer minorities need no longer join whites to live in high-income communities.

While this rich literature has made significant contributions to our understanding of the equilibrium properties of segregation, it has almost completely ignored the role played by public 
goods and/or location-specific amenities in the process of segregation. ${ }^{1}$ This is an important shortcoming because, as the above epigraph illustrates, many of the policy remedies for reducing group inequity focus specifically on investments in minority communities. Investments in education are only one example. In addition, the U.S. Department of Housing and Urban Development (HUD) provides Community Development Block Grants (totaling \$125B since 1974); the US EPA's Superfund and Brownfields programs clean up contaminated sites and encourage redevelopment; enterprise zones provide tax incentives for businesses; and the 1992 Federal Housing Enterprises Financial Safety and Soundness Act steers Fannie and Freddie investments to low-income and minority communities. Clearly, such place-based interventions play a central role in efforts to address social concerns associated with segregation.

In this paper, we advance the literature by introducing an exogenous location-specific public good (to be manipulated by public policy) into a model of group segregation. In this sense, we combine features of the segregation and public goods literatures. ${ }^{2}$ First, following the tradition of Schelling $(1969,1971)$, we consider preferences for the endogenous demographic make-up of the community. ${ }^{3}$ Second, following the tradition of Tiebout (1956), we include heterogeneity in willingness to pay for public goods. In particular, we adapt a model of vertically differentiated communities from Epple, Filimon, and Romer (1984), a model used in other recent and related work (Banzhaf and Walsh 2008, Sethi and Somanathan 2004).

We combine these two traditions into a general equilibrium model in which households choose a community based on both its endogenous demographics and its exogenous public good. We then characterize the equilibria of such a model and derive the comparative statics of policy

\footnotetext{
${ }^{1}$ An important exception is Becker and Murphy (2000). Using several compelling examples, they point out how, even in a very simple model, the presence of an exogenous amenity can radically change the demographic sorting dynamics. In this paper, we extend that theme, characterizing the way exogenous public goods and demographics interact under more general conditions.

${ }^{2}$ Glaeser and Scheinkman (2003) show how these two models can be nested in a more general social interaction model.

${ }^{3}$ Throughout our analysis a fundamental assumption is that individuals of a given type tend toward living together due to preferences to live with individuals of their own type. We note, though, that identical results would be obtained if the model assumed that concentrations of individuals of a given type lead to social spillovers that disproportionately benefit that type (i.e. concentrations of businesses, community networks, restaurants, non-profit services, etc.).
} 
shocks to the local public goods. The model generates several results regarding the importance of place-based amenities. First, we establish that, even when sorting is driven by tastes for the exogenous public good and not by demographic tastes, some racial segregation will result, with the richer group enjoying higher levels of the public good. Second, we show that introducing tastes for endogenous demographic composition can drive further segregation, as suggested by Schelling's "tipping model." By the same token, we show that differences in public good levels can alter the responses to demographic composition. Such dynamics may explain some of the variation that Card, Mas and Rothstein (2008) observe in their empirical estimates of tipping points in U.S. Cities. As a pragmatic matter, this increased segregation is likely to further the differences in the average level of the public good enjoyed by the two groups. Finally, we show that place-based interventions that improve the public good in a low-quality, high-minority community may actually increase group segregation, as richer minorities are more likely to migrate into the community following the improvement. Essentially, when differences in public goods become less important, group-based sorting begins to dominate income-based sorting on the public good.

In the final section of the paper, we use large changes in the distribution of air pollution from industrial facilities that occurred in California between 1990 and 2000 to illustrate the predictions of the model. Consistent with our model's predictions, we find that large scale improvements in the dirtiest sites are associated with increased racial sorting on exposure to toxic air pollution.

\section{Theoretical Model}

In this section, we develop a model of the links between race, demographic composition, public goods, and location choice. In the recent literature, the model is most similar to work by Becker and Murphy (2000), Sethi and Somanathan (2004) and Banzhaf and Walsh (2008), but differs from these papers in several important respects. It resembles Becker and Murphy (2000) in combining preferences for an exogenous public good with the endogenous demographic community, but differs in going beyond their simple 2-person model to incorporate continuous income distributions and heterogeneity in the willingness to pay for amenities. Generalizing their model in this way is crucial for evaluating income-based segregation. Our model also differs 
from theirs in that each group prefers to be with their own type, rather than a particular "high type." At the same time, our model resembles Sethi and Somanathan (2004) and Banzhaf and Walsh (2008) in adapting the vertically differentiated framework of Epple et al. (1984). But it differs from Banzhaf and Walsh (2008), who only consider the exogenous good, in including racial groups and demographic preferences. And it differs from Sethi and Somanathan (2004) in including an exogenous public good. ${ }^{4}$ Including this public good is obviously essential to analyzing the kinds of policy shocks that motivate our paper.

\subsection{Model Basics}

We consider a model with two communities, $j \in\{C 1, C 2\}$, each composed of an identical set of fixed-size housing stock with measure 0.5. The price of this fixed housing unit is $P^{j}$. Residents of these communities comprise two demographic types, $r \in\{b, w\}$. Type $b$, the minority, has measure $\beta<0.5$ and type $w$ has measure $(1-\beta)$. One obvious interpretation of these types is as racial groups ( $w$ for white and $b$ for blacks). However, in principle they could represent any pair of groups with the minority group being poorer.

There is heterogeneity in income $Y$ within each type, which is described by the continuous distribution functions $F_{r}(Y)$. We impose the following two assumptions on the income distributions of type $b$ and $w$ individuals:

$$
F_{w}(Y) \leq F_{b}(Y) \text { for all } Y
$$

and

$$
Y_{b}^{\operatorname{Min}}=Y_{w}^{\operatorname{Min}}<F_{w}^{-1}\left[\frac{\cdot 5 *(1-2 \beta)}{1-\beta}\right]<Y_{b}^{\operatorname{Max}} \leq Y_{w}^{\operatorname{Max}} .
$$

The first condition requires that the population of type- $w$ individuals is richer than the population of type- $b$ individuals in the sense of first-order stochastic dominance. The second condition limits the difference in income distributions between the two groups. In particular, it states that

\footnotetext{
${ }^{4} \mathrm{We}$ also provide a more general characterization of the equilibria of our model, including integrated and segregated equilibria. Sethi and Somanathan (2004) focus on integrated equilibria.
} 
some positive measure of each group falls in the top half of the pooled income distribution.

Each individual is assumed to consume one unit of housing and to have preferences over a numeraire good $x$ (with a price set to unity), an exogenous community public good level $G^{j}$ and endogenous community demographic composition. Tastes for demographic composition are captured by $D_{r}^{j}=D_{r}\left(P R O P_{r}^{j}\right)$, where $P R O P_{r}^{j}$ is the proportion of residents in community $j$ who are of type $r$. Individuals of each type experience the same service flow from the public good. However, they view the demographic composition differently, so $D$ is indexed by type $r$ as well as location $j$.

Conditional on choosing location $j$, utility for an individual of type $r$ and income $Y$ is given by equation (3):

$$
U_{r}^{j}=U\left[Y-P^{j}, V\left(G^{j}, D_{r}^{j}\right)\right]=U\left[x, V_{r}^{j}\right] .
$$

The function $U(\cdot)$ is continuous and increasing at a decreasing rate in both of its arguments, and $V(\cdot)$ is increasing in both arguments. More compactly, let $V_{r}^{j}=V\left(G^{j}, D_{r}^{j}\right)$. Consumption $x$ is simply income net of housing costs. We impose the Inada condition that $U_{x} \rightarrow \infty$ as $x \rightarrow 0$. We also impose the following condition on $D_{r}$ :

$$
D_{w}(1-2 \alpha \beta)>D_{w}(1-2(1-\alpha) \beta) \forall \alpha \in[0,0.5)
$$

and

$$
D_{b}(2(1-\alpha) \beta)>D_{b}(2 \alpha \beta) \forall \alpha \in[0,0.5) \text {. }
$$

This condition guarantees that when $G^{1}=G^{2}$, for any feasible sorting, each type prefers the community with more of its own type. For example, if $\beta=0.25$, the condition requires that type- $w$ individuals prefer an all- $w$ community to a community with less than $50 \% w$ and type- $b$ individuals prefer a community that is more than $50 \%$ type $b$ to an all- $w$ community. This condition does not imply that preferences are monotonic. To the contrary, in general this assumption is consistent with a wide range of preferences including for example any symmetric "bliss point" specification, $D_{r}^{j}=g\left[\operatorname{abs}\left(P R O P_{r}^{j}-\rho_{r}\right)\right]$, where $g^{\prime}<0,1-\beta \leq \rho_{w} \leq 1$, and $\beta \leq \rho_{b} \leq 1$. While this restriction is not necessary for solving the model, we restrict the preference domain to these 
cases because they are consistent with US racial preferences previously estimated in the literature. $^{5}$

Finally, without loss of generality, we assume that when public good levels differ the level of the public good is higher in Community 2 than in Community $1: G^{C 2}>G^{C 1}$. And, because we are working with an assignment model, to close the model we normalize the price of housing in Community 1 to zero: $P^{C 1}=0$. This normalization allows us to work with households' willingness to pay to live in $C 2$, given $V_{r}^{j}$ and $Y$. Denote this willingness to pay as $B i d_{Y r}$.

Equilibrium in the model is characterized by a sorting of individuals across the two communities and a price level in Community $2, P^{C 2}$, such that:

E1. In each community, for each type, $P R O P_{r}^{j}$ arises from the sorting of individuals:

$$
P R O P_{r}^{j}=\frac{\mu\left(S_{r, j}\right)}{0.5}
$$

where $\mu\left(S_{r, j}\right)$ is the measure of the set of individuals of type $r$ choosing community $j$.

E2. Each individual resides in his preferred community. That is, for all type- $r$ individuals choosing to live in community $j$ :

$$
U\left[Y_{i}-P^{j}, V\left(G^{j}, D_{r}^{j}\right)\right] \geq U\left[Y_{i}-P^{-j}, V\left(G^{-j}, D_{r}^{-j}\right)\right]
$$

E3. Housing markets clear, so the measure of individuals choosing each community is equal to 0.5 .

The structure of the model allows us to simplify the characterization of the sorting of individuals across communities. Specifically, the concavity of $U(\mathrm{)})$ in the numeraire and in $V($ ), combined with the assumption that each household consumes an identical and fixed quantity of housing, implies that within each type preferences satisfy the "single crossing" property in $P^{j}$ and $V_{r}^{j}$. This in turn implies that equilibria in the model will exhibit stratification by income

\footnotetext{
${ }^{5}$ In particular, the survey literature suggests that the appropriate levels for $\rho_{w}$ and $\rho_{b}$ are around 0.9 and 0.5 respectively (Farley et al. 1978 and Farley and Krysan 2002). Furthermore, it is reasonable to focus on this portion of the parameter space, as such preferences are consistent with socially relevant phenomenon of "white-flight" or neighborhood tipping recently documented by Card, Mas, and Rothstein (2008), as well as the price premium for white communities documented by Cutler, Glaeser, and Vigdor (1999).
} 
within each type. ${ }^{6}$ In other words, in equilibrium, for each type there is a boundary income, $\bar{Y}_{r}$, such that all individuals of type $r$ with incomes greater than $\bar{Y}_{r}$, choose to live in the community that that type views as more desirable (i.e. the community with the higher values of $V_{r}^{j}$ ). ${ }^{7}$

In analyzing equilibria in the model, it is particularly useful to consider these boundary individual's willingness to pay to be in Community 2 (relative to Community 1). Define $\operatorname{Bid}_{\bar{Y}_{r}}$ to be the price level in Community 2 that makes these individuals indifferent between the two communities. Recalling that $P^{C l}$ is normalized to $0, \operatorname{Bid}_{\bar{Y}_{r}}$ is implicitly defined by:

$$
U\left[\bar{Y}_{r}, V\left(G^{C 1}, D_{r}^{C 1}\right)\right]=U\left[\bar{Y}_{r}-\operatorname{Bid}_{\bar{Y}_{r}}, V\left(G^{C 2}, D_{r}^{C 2}\right)\right]
$$

By definition, $B i d_{\bar{Y}_{r}}$ makes these boundary individuals indifferent between the two communities. Note that the continuity of $U($.$) and F_{r}($.$) implies that B i d_{\bar{Y}_{r}}$ is continuous in $G^{j}$ and $D^{j}$.

\subsection{Equilibria in the Model}

To provide intuition about the equilibrium properties of the model, we begin by working through a four-step process for evaluating the potential for different demographic sortings to be supported as equilibria. In this section, we also build intuition by working with one specific example.

In the first step, we note that the entire demographic profile of a given sorting of households can be expressed solely as a function of $P R O P_{w}^{C 1}$, the proportion of Community 1 that is type $w$. In particular, if one knows the proportion of Community 1 that is type $w$, the proportion of Community 1 that is type $b$ follows directly. Similar logic identifies $P R O P_{w}^{C 2}$ and $P R O P_{b}^{C 2}$ :

$$
P R O P_{b}^{C 1}=1-P R O P_{w}^{C 1}
$$

\footnotetext{
${ }^{6}$ See Epple et al. (1984) for discussion of single crossing and stratification in equilibrium sorting models.

${ }^{7}$ Formally, given $V_{r}^{j}>V_{r}^{k}$, the boundary income is defined as that income at which for all $Y \geq \bar{Y}_{r}, U_{Y, r}^{j} \geq U_{Y, r}^{k}$. When individuals of type $r$ reside in both communities, a type $r$ individual with the boundary income is indifferent between the two communities. However, there are equilibria where all type- $b$ individuals locate in the same community. In this case $\bar{Y}_{b}=Y_{b}^{M i n}$ when $V_{b}^{j}$ is higher in the community in which they reside and $\bar{Y}_{b} \geq Y_{b}^{\text {Max }}$ when $V_{b}^{j}$ is higher in the other community.
} 


$$
\begin{gathered}
P R O P_{w}^{C 2}=2(1-\beta)-P R O P_{w}^{C 1} ; \text { and } \\
P R O P_{b}^{C 2}=1-P R O P_{w}^{C 2}=P R O P_{w}^{C 1}+2 \beta-1 .
\end{gathered}
$$

We graph these relationships in Panel 1 of Figure 1. Given the requirement that housing markets clear (equilibrium condition E3), these relationships are purely tautological and are the same for all possible parameterizations of the model. Given the complete identification of $P R O P_{r}^{j}$, the demographic components of $V_{r}^{j}($.$) can be expressed as a function of P R O P_{w}^{C 1}, D_{r}^{j}=$ $D_{r}^{j}\left(P R O P_{w}^{C 1}\right)$.

In the second step, we compute $V_{r}^{j}=V\left(G^{r}, D_{r}^{j}\right)$ for both communities and types, again as a function of $P R O P_{w}^{C 1}$. Panel 2 of Figure 1 illustrates one particular specification with blisspoint preferences over demographic composition. In particular, the figure illustrates results for $\beta=0.25, D_{r}^{j}=\left(P R O P_{r}^{j}-\rho_{r}\right)^{2}, \rho_{b}=0.5, \rho_{w}=0.9$, and $V_{r}^{j}=D_{r}^{j}+G^{j}$. That is, $V(\cdot)$ is separable in $D$ and $G$, and $D$ is defined by a quadratic function around a bliss point $\rho$, with type $w$ preferring more segregation. (As noted above, this parameterization of $D_{r}$ is consistent with previous findings for racial attitudes and in the US.) The utility function $U(\cdot)$ is Cobb-Douglas in consumption and $V$, with an expenditure share of 0.75 on consumption. Incomes are uniformly distributed with $Y_{r}^{\min }=0, Y_{b}^{\max }=1$, and $Y_{w}^{\max }=1.1$. Finally, public good levels are identical: $G^{C 1}=G^{C 2}=1$.

The figure shows that, for this example, the utility received by type $w$ in $C l$ is increasing in $P R O P_{w}^{C 1}$ up to the bliss point at 0.9 , at which point it begins to fall. Type- $w$ 's utility in $C 2$ likewise is increasing in $P R O P_{w}^{C 2}$ up to the same bliss point, but this is mapped in the figure as being decreasing in $P R O P_{w}^{C 1}$ up to the bliss point where $P R O P_{w}^{C 1}=0.6$ (which is where $P R O P_{w}^{C 2}$ $=0.9$ ). On the other hand, type- $b$ utility in $C 1$ is decreasing in $P R O P_{w}^{C 1}$ while type- $b$ utility in $C 2$ is increasing in $P R O P_{w}^{C 1}$. In this example, since $\beta=0.25$, type $b$ is always below its bliss point of 0.5 . Note that even with these bliss point preferences, both types always prefer the community with the larger percentage of their own type. This is guaranteed by our condition on demographic preferences and the set of feasible profiles identified in Panel 1. Finally, note that because in this example $G^{C 1}=G^{C 2}$, both groups are indifferent when the community compositions 
are identical, which occurs where $P R O P_{w}^{C 1}=0.75$.

In the third step, we identify the boundary incomes associated with the sorting implied by each value of $P R O P_{w}^{C 1}$. These boundary incomes are a function of the utility values computed in the previous step and the income distributions. For example, suppose $\beta=0.25$ and $P R O P_{w}^{C 1}$ is 0.6. By Equation 5, PROP $P_{w}^{C 2}$ is 0.9. In turn, it follows that $2 / 5$ of type $w$ are in Community 1. Suppose further that with $P R O P_{w}^{C 1}=0.6$, the values of $G^{j}$ imply that type $w$ individuals prefer Community 2 . Then by single crossing, we know that $\bar{Y}_{w}$ must be equal to $F_{w}^{-1}\left[\frac{2}{5}\right]$. In general,

$$
\begin{aligned}
& \bar{Y}_{b}=\left\{\begin{array}{cc}
F_{b}^{-1}\left[\frac{.5 *\left(P R O P_{w}^{C 1}+2 \beta-1\right)}{\beta}\right] & \text { if } \quad V_{b}^{C 1}>V_{b}^{C 2}, \\
F_{b}^{-1}\left[\frac{.5 *\left(1-P R O P_{w}^{C 1}\right)}{\beta}\right] & \text { if } \quad V_{b}^{C 2}>V_{b}^{C 1},
\end{array}\right. \\
& \bar{Y}_{w}=\left\{\begin{array}{ccc}
F_{W}^{-1}\left[\frac{.5 *\left(2-2 \beta-P R O P_{w}^{C 1}\right)}{1-\beta}\right] & \text { if } & V_{w}^{C 1}>V_{w}^{C 2}, \\
F_{W}^{-1}\left[\frac{.5 * P R O P_{w}^{C 1}}{1-\beta}\right] & \text { if } & V_{w}^{C 2}>V_{w}^{C 1} .
\end{array}\right.
\end{aligned}
$$

We can similarly characterize the derivatives of these boundary incomes with respect to $\operatorname{PCTW}^{C 1}$ :

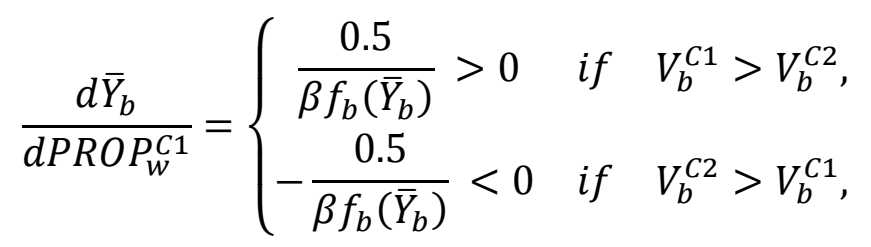

$$
\begin{aligned}
& \frac{d \bar{Y}_{w}}{d P R O P_{w}^{C 1}}=\left\{\begin{array}{ccc}
-\frac{0.5}{(1-\beta) f_{w}\left(\bar{Y}_{w}\right)}<0 & \text { if } & V_{w}^{C 1}>V_{w}^{C 2} \\
\frac{0.5}{(1-\beta) f_{w}\left(\bar{Y}_{w}\right)}>0 & \text { if } & V_{w}^{C 2}>V_{w}^{C 1}
\end{array}\right.
\end{aligned}
$$

Panel 3 shows, for our example, the boundary incomes as a function of $P R O P_{w}^{C 1}$. Because this example uses uniform income distributions, the boundary incomes are linear in $P R O P_{w}^{C 1}$. When $P R O P_{w}^{C 1}$ is below $1-\beta$, type- $w$ individuals prefer Community 2 . As a result, 
single-crossing implies that they will sort such that the richest type- $w$ individuals locate in $C 2$. Consequently, the boundary income is that of the poorest type- $w$ individual in $C 2$ (alternatively the richest type-w individual in $C 1$ ). As $P R O P_{w}^{C 1}$ at first increases toward 0.75 , the measure of type- $w$ individuals living in $C 2$ must decrease. Thus, the boundary income must increase. But when $P R O P_{w}^{C 1}$ increases above 1- $\beta$, the relative ranking of the communities changes and rich type- $w$ individuals now locate in $C 1$. Thus, the boundary income is now decreasing in $P R O P_{w}^{C 1}$. Because in this example the community switch occurs where type- $w$ individuals are equally distributed between the two communities, the boundary income function is continuous with a kink at the point where $V_{r}^{1}=V_{r}^{2}$. As discussed below, in cases where public good levels differ and indifference between the two communities occur where $P R O P_{w}^{C 1} \neq 1-\beta$, there will be a discontinuity in the boundary income function.

While the boundary income function for type $b$ looks similar to that of the type $w$, the underlying process is different. When $P R O P_{w}^{C 1}$ is below 1- $\beta$, type- $b$ individuals prefer Community 1 . Thus, by single crossing, the type- $b$ boundary income will be that of the poorest type- $b$ individual in $C 1$ (alternatively the richest type- $b$ individual in $C 2$ ). At the extreme, when $P R O P_{w}^{C 1}=1-2 \beta=0.5$, all type- $b$ individuals are in $C 1$ and $\bar{Y}_{b}=Y_{b}^{M i n}=0$.

Based on the discussion to this point, we make the following observations.

Observation 1. Some type- $w$ individuals always live in both communities. This must be the case because the measure of type- $w$ individuals is greater than 0.5 . More specifically, the share of type $w$ in any community can never fall below $1-2 \beta$. In contrast, all type- $b$ individuals can reside in only one of the two communities.

Observation 2. When $V_{w}{ }^{C l} \neq V_{w}{ }^{C 2}$, there is some $\bar{Y}_{w}$ at which type-w individuals are indifferent. All type- $w$ individuals with income higher than $\bar{Y}_{w}$ will reside in the more desirable (to $w$ ) community and poorer type- $w$ individuals will live in the community that type- $w$ individuals find less desirable. Moreover, $\bar{Y}_{w}$ can never drop below $F_{w}^{-1}[(0.5-\beta) /(1-\beta)]$. In contrast, it is possible that $b$ 's boundary income may fall to $Y_{b}^{\mathrm{Min}}$.

Observation 3. The community that type $w$ perceives as more desirable will be more expensive: $V_{w}{ }^{C 2} \geq V_{w}{ }^{C 1} \leftrightarrow P^{C 2} \geq 0$. This relationship must hold. Otherwise, every type $w$ individual would prefer to live in the community with higher $V_{w}$ and lower price, and the demand for housing would exceed supply in that community. Further, $P^{C 2}=\operatorname{Bid}_{\bar{Y}_{w}}$. 
These observations are general to the model and do not depend on the specific assumptions underlying the example depicted in Figure 1.

As noted in Observation 1 , because $\beta<0.5$, it is possible for all type- $b$ individuals to live in the same community. We will refer to equilibria where all type- $b$ individuals live in the same community as "segregated" and equilibria where some type- $b$ individuals live in both communities as "integrated." We make the following observations about these two cases.

Observation 4. For segregation of types with all type- $b$ individuals locating in $C 1$ to be supportable as an equilibrium, it must be the case that $\operatorname{Bid}_{\bar{Y}_{b}} \leq B i d_{\bar{Y}_{w}}$. (Otherwise, if $\operatorname{Bid}_{\bar{Y}_{b}}>B i d_{\bar{Y}_{w}}$, then the boundary type- $b$ individual would outbid the boundary type-w individual for housing in C2.) In particular, if $V_{b}{ }^{C 2}>V_{b}{ }^{C l}$ and $V_{w}{ }^{C 2}>V_{w}{ }^{C 1}$, then $B i d_{\bar{Y}_{w}} \geq$ $\operatorname{Bid}_{\bar{Y}_{b}}>0$. If $V_{b}{ }^{C l}>V_{b}{ }^{C 2}$ and $V_{w}{ }^{C 2}>V_{w}{ }^{C 1}$ then $\operatorname{Bid}_{\bar{Y}_{w}}>0>B i d_{\bar{Y}_{b}}$. And if $V_{b}{ }^{C 1}>V_{b}{ }^{C 2}$ and $V_{w}{ }^{C 1}>V_{w}{ }^{C 2}$, then $0>B i d_{\bar{Y}_{w}} \geq B i d_{\bar{Y}_{b}}$. Note also that if $V_{b}{ }^{C l}>V_{b}{ }^{C 2}$, then $\bar{Y}_{b}=Y_{b}^{\text {Min }}=$ 0 . Otherwise, $\bar{Y}_{b}=Y_{b}^{\mathrm{Max}}$. The opposite and symmetric cases hold for equilibria where all type- $b$ individuals locate in $C 2$.

Observation 5. In any integrated equilibrium, both types must agree on which community is more desirable, and $B i d_{\bar{Y}_{w}}=B i d_{\bar{Y}_{b}}$. Additionally, some members of each type must be willing to pay to live in the more desirable community $\left(Y_{b}^{\operatorname{Min}}<B i d_{\bar{Y}_{W}}=B i d_{\bar{Y}_{b}}<\right.$ $\left.Y_{b}^{\mathrm{Max}}\right)$.

The upshot of these observations is that equilibria can be identified by an analysis of the bids of individuals at the boundary incomes. We use the term "boundary income bid function" for the mapping from $P R O P_{w}^{C 1}$ to these bids. Note that the boundary income bid function for type $r$ is not the willingness to pay function for a specific individual, but a bid function over an endogenous income level (the boundary incomes associated with each sorting).

If at any integrated allocation the two groups' boundary income bid functions are equal, $\operatorname{Bid}_{\bar{Y}_{W}}=B i d_{\bar{Y}_{b}}$, then that integrated allocation can be supported as an equilibrium. Alternatively, a segregated equilibrium with $C 2$ all-w exists if at such an allocation $B i d_{\bar{Y}_{b}} \leq B i d_{\bar{Y}_{w}}$. Finally, a segregated equilibrium with $C 1$ all-w exists if at such an allocation $B i d_{\bar{Y}_{w}} \leq B i d_{\bar{Y}_{b}}$.

The derivative of the boundary income bid function with respect to $P R O P_{w}^{C 1}$ is given by Equation (10): 


$$
\frac{d B i \bar{Y}_{\bar{Y}_{r}}}{d P R O P_{W}^{C 1}}=\left[\frac{d \bar{Y}_{r}}{d P R O P_{w}^{C 1}}\left(U_{x}^{C 2}-U_{x}^{C 1}\right)+\left(U_{V}^{C 2} V_{D}^{C 2} \frac{d D_{r}^{C 2}}{d P R O P_{w}^{C 1}}-U_{V}^{C 1} V_{D}^{C 1} \frac{d D_{r}^{C 1}}{d P R O P_{w}^{C 1}}\right)\right] \frac{1}{U_{x}^{C 2}}
$$

where $U_{x}^{j}$ is the derivative of the utility function with respect to the numeraire, evaluated in Community $j$ at the appropriate income (i.e. $\bar{Y}_{r}$ ). All other derivatives are similarly defined. The expression shows two effects. The first term inside the brackets captures the effect of the change in the boundary income that is associated with the change in $P R O P_{w}^{C 1}$. The second term inside the brackets captures the effect of changes in the $V(\cdot)$ function that are associated with an increase in $P R O P_{w}^{C 1}$.

Panel 4 of Figure 1 plots the boundary income bid functions associated with the previously defined example. Recall from the second step that, because the $G$ 's are equal in the two communities, when $P R O P_{w}^{C 1}=0.75$ the demographic compositions are identical as well, so both groups are indifferent between communities at that point. Accordingly, Panel 4 shows that, for each type, the boundary income bid function is zero when $P R O P_{w}^{C 1}=0.75$.

Type- $w$ individuals prefer Community 2 when $P R O P_{w}^{C 1}<0.75$, so the bid function is positive. Conversely, when $P R O P_{w}^{C 1}>0.75$, type- $w$ individuals prefer Community 1 and the bid function is negative. Using Equation (10), we find that the type- $w$ boundary income bid function is monotonically decreasing in $P R O P_{w}^{C 1}$ for this example. This relationship arises because the utility effect of changes in $P R O P_{w}^{C 1}$, shown in the second term of Equation (10), is negative and always dominates the boundary income effect, shown in the first term of Equation (10), which is positive.

For type- $b$ individuals, preferences for the communities are the reverse of those of typew. The bid function is always negative for $P R O P_{w}^{C 1}<0.75$ and always positive for $P R O P_{w}^{C 1}>$ 0.75. In terms of the slope of the bid function, the basic dynamics are the same as with type- $w$ individuals, except that for very low or very high levels of $P R O P_{w}^{C 1}$ the change associated with the boundary income dominates the change associated with closing the gap in $V(\cdot)$. This result differs from that for type-w individuals because of the steeper slope of $d \bar{Y}_{b} / d P R O P_{w}^{C 1}$, which arises from the fact that there are fewer type- $b$ individuals. 
Evaluating the figure, we can see that this example has three equilibria. At the far left, type- $w$ individuals are willing to pay to live in Community 2 , type- $b$ individuals are not, and $C 2$ is all-w. At the far right is the opposite and symmetric segregated equilibrium. In the middle, there is an integrated equilibrium in which the two communities have the same composition, and all individuals of both types are indifferent between the two communities.

\subsection{Characterizing the equilibria and their comparative statics}

We now characterize the equilibria and comparative statics of the model. We first establish the existence of equilibria in the model.

\section{Proposition 1.}

For preference functions and income distributions satisfying conditions (1) through (3) in Section 2.1, there is at least one allocation that satisfies equilibrium conditions E.1 to E3.

\section{Proof.}

Consider the sorting at $P R O P_{w}^{C 1}=1-2 \beta$. (This is the point where $P R O P_{w}^{C 2}=1$ and is depicted as the left-hand side of Panel 4 in Figure 1). At this point either $B i d_{\bar{Y}_{b}} \leq B i d_{\bar{Y}_{W}}$ or $B i d_{\bar{Y}_{b}}>B i d_{\bar{Y}_{W}}$. In the former case this point represents a segregated equilibrium and thus existence is trivial. Consider now the sorting at $P R O P_{W}^{C 1}=1$. Again, at this point either $B i d_{\bar{Y}_{W}} \leq B i d_{\bar{Y}_{b}}$ or $B i d_{\bar{Y}_{W}}>B i d_{\bar{Y}_{b}}$. And again, in the former case, this point represents a segregated equilibrium. Finally, we must consider the possibility that $\operatorname{Bid}_{\bar{Y}_{b}}>\operatorname{Bid}_{\bar{Y}_{w}}$ at $P R O P_{w}^{C 1}=1-2 \beta$ and $\operatorname{Bid}_{\bar{Y}_{w}}>\operatorname{Bid}_{\bar{Y}_{b}}$ at $P R O P_{w}^{C 1}=1$. But in this case, by continuity, the boundary income bid functions must cross at some point, where $B i d_{\bar{Y}_{w}}=B i d_{\bar{Y}_{b}}$, which is also an equilibrium.

In addition to the existence of such equilibria, we are also concerned with stability of equilibria. We adopt the following definition of local stability.

\section{Definition}

Let an epsilon set of marginal individuals of type $r$ in community $j$, be defined as follows:

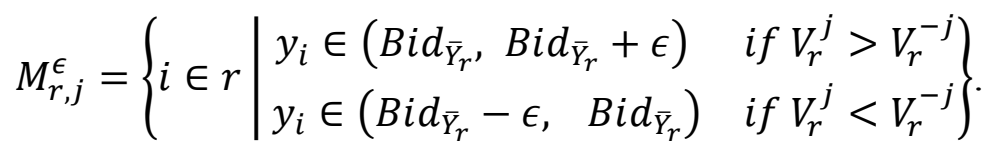

An equilibrium is locally stable if there exists a $\delta$, such that for any 4-tuple of epsilon sets $\left(M_{w, 1}^{\epsilon}, M_{w, 2}^{\epsilon}, M_{b, 1}^{\epsilon}, M_{b, 2}^{\epsilon}\right)$ each having measure $\mu<\delta$, switching $M_{w, 1}^{\epsilon}$ with $M_{b, 2}^{\epsilon}$ 
across the two communities results in $\operatorname{Bid}_{\bar{Y}_{b}}>B i d_{\bar{Y}_{W}}$ and switching $M_{w, 2}^{\epsilon}$ with $M_{b, 1}^{\epsilon}$ across the two communities results in $\operatorname{Bid}_{\bar{Y}_{w}}>\operatorname{Bid}_{\bar{Y}_{b}} \cdot{ }^{8}$

Essentially, this definition requires that when a small set of "almost indifferent" type- $w$ individuals in one community switch with a small set of "almost indifferent" type- $b$ individuals in the other community, they prefer to switch back. It insures that individuals moved from Community 2 will outbid the individuals moved from Community 1 ; thus reversing the perturbation and restoring the initial equilibrium. When this condition is not met, an equilibrium is unstable and the perturbation causes the communities to tip toward segregation (or toward a different integrated equilibrium).

As discussed above, equilibria occur either at corners (the case of segregation) or in the interior (the case of integration). Whenever corner equilibria exist, they will be locally stable. For interior solutions, it is straightforward to demonstrate that the local stability conditions are satisfied whenever the type- $b$ boundary income bid function crosses the type- $w$ boundary income bid function from above.

Additionally, by analogy to a "regular" Arrow-Debreu economy, we can define a regular sorting as one in which, at each point where $\operatorname{Bid}_{\bar{Y}_{W}}=B i d_{\bar{Y}_{b}}, \frac{d B i d_{\bar{Y}_{W}}}{d P R O P_{W}^{C 1}} \neq \frac{d B i d_{\bar{Y}_{b}}}{d P R O P_{W}^{C 1}}$. In the case of a regular sorting there are an odd number of equilibria. Moreover, if there are $n$ such equilibria, $(n+1) / 2$ are stable, the analog of the index theorem in our model. ${ }^{9}$

\footnotetext{
${ }^{8}$ In the degenerate case where $V_{r}^{1}=V_{r}^{2}$, this definition collapses to switching any two arbitrary sets of individuals having measure $\mu$.

${ }^{9}$ The proof follows the logic of Proposition 1, and we sketch it briefly. Consider the sorting at $P R O P_{w}^{C 1}=1-2 \beta$ and consider two cases. In case $1, B i d_{\bar{Y}_{b}} \leq B i d_{\bar{Y}_{w}}$ and this is a stable equilibrium (with $C 2$ all-w). Consider three subcases. (1a) If the bid functions never cross, then this is the only equilibrium. (1b) If the bid functions cross an even number of times, there is only the one segregated equilibrium plus the even integrated equilibria, totaling an odd number of equilibria. In addition, half the integrated equilibria will occur with type- $b$ 's boundary income bid function cutting type- $w$ 's from above, indicating stability. Thus, $(n+1) / 2$ are stable. (1c) If the bid functions cross an odd number of times, there will be a second segregated equilibrium at $P R O P_{w}^{C 1}=1$, with $\operatorname{Bid}_{\bar{Y}_{w}} \leq \operatorname{Bid}_{\bar{Y}_{b}}$. That is, there will be an odd number of integrated equilibria plus two segregated equilibria, totaling an odd number of equilibria. In addition, if there are $m$ integrated equilibria, $(m-1) / 2$ will be stable. With $n=m+2$, this means there will be $(n+1) / 2$ stable equilibria again. Though we omit them for brevity, these sub-cases can be repeated for case 2 , where $\operatorname{Bid}_{\bar{Y}_{b}}>\operatorname{Bid}_{\bar{Y}_{w}}$ at $P R O P_{w}^{C 1}=1-2 \beta$, to complete the proof.

Note here the importance of the notion of the "regular" economy. Without it, there may be additional equilibria where the two groups' boundary income bid functions are just tangent, or even an interval of equilibria. Debreu
} 
The example illustrated in Figure 1 has three equilibria, and only the two symmetric segregated equilibria are stable. This result is not limited to this example. For any specification satisfying the general preferences in Section 2.1, the following proposition holds.

\section{Proposition 2.}

Whenever $G^{C 1}=G^{C 2}$, there will be three equilibria: two stable segregated equilibria with $P R O P_{w}^{C 1}=1$ and $P R O P_{w}^{C 1}=1-2 \beta$, respectively, and one unstable integrated equilibrium with $P C T w^{C l}=1-\beta$.

Proof: See the appendix.

When there are no differences in the public good, individuals sort solely based on demographics, resulting in segregation.

We now turn to an analysis of cases where public good levels differ across communities. To build intuition for how relationships change when public goods differ, Figure 2 replicates the example from Figure 1 but now for a case with unequal public good levels $\left(G^{C 1}=0.9\right.$ and $\left.G^{C 2}=1\right)$. Because the set of feasible demographic compositions is independent of public good levels, the first panel of Figure 2 is identical to Figure 1. Comparing Panel 2 in Figure 2 to Figure 1 reveals that when $G^{C 1}$ falls, $V_{r}^{C 1}$ shifts down for both types. As a result, type- $b$ individuals are now indifferent between the two communities when $P R O P_{w}^{C 1}=0.65$ (instead of at .75 in the previous case where $G^{C 1}=G^{C 2}$ ). For type- $w$ individuals the indifference point is now at $P R O P_{w}^{C 1}=0.92$ (versus 0.90 in the previous case).

Panel 3 shows the impact of the differential public good levels on the boundary income functions. When public goods were equated across communities, both types were indifferent at the point where $P R O P_{w}^{C 1}=P R O P_{w}^{C 2}$. As a result, even though relative preferences for communities switch at this point, reversing the income sorting, the boundary income functions were continuous (though kinked) at the indifference point. Differential public good levels separate the indifference point for the two types moving them away from equal sorting. Consequently, the

(1970) shows that the equilibria in an Arrow-Debreu economy are regular "almost everywhere" in the set of preference parameters and income distributions. Although a proof is beyond the scope of this paper, reasoning analogously it seems likely that the set of parameters that would generate irregular sorting have measure zero in the parameter space. Certainly, we have never found an example with irregular sortings. 
boundary income functions now have a discontinuity at each type's indifference point.

Finally, Panel 4 of Figure 2 presents the boundary income bid functions under the new public good levels. In spite of the discontinuity in boundary incomes, The boundary bid functions are continuous at this point. This continuity, which will always hold, occurs because the bid function at the point of indifference is by definition equal to zero and approaches zero continuously from both sides. In terms of potential equilibria, the model remains qualitatively similar to the case where the public good levels were equal. There are still two stable segregated equilibria and one unstable integrated equilibrium, with the location of the unstable integrated equilibrium now shifted slightly to the right to where $P R O P_{w}^{C 1}=0.76$. Thus, for small differences in public good levels, it is possible to support a segregated equilibrium with all type- $b$ individuals in the high public good community. However, comparison of the bid functions in Figures 1 and 2 suggest that, at least for this example, if the public good gap were to increase further, then this equilibrium will no longer be supported. As we shall see below, this result holds in general.

As the public good gap increases, it becomes difficult to make general statements regarding the character of equilibria. As is clear from an examination of Equation 10, the slopes of the bid functions are highly sensitive to local variations in the density of the income functions and the relative curvatures of the utility functions. For instance, it is relatively straightforward to generate examples with multiple segregated and multiple stable and unstable integrated equilibria when the public good differentials are moderate in size.

Nevertheless, the model does provide sharp predictions regarding equilibria for cases with "small" or "large" differences in public goods, and a comparison of these two polar cases provides important policy insights. We begin by considering the case with small differences in the public goods levels. As stated in Proposition 2, the case where the level of public goods is the same in each community always has one unstable integrated equilibrium and two symmetric stable segregated equilibria. This proposition extends to a measure of $G^{j}$ as stated in Proposition 3.

\section{Proposition 3}

For any given level of $G^{C 2}$, there exists $\tilde{G}^{C 1}<G^{C 2}$ such that for all $\tilde{G}^{C 1}<G^{C 1}<G^{C 2}$ 
there will be exactly three equilibria, two symmetric stable segregated equilibria and one unstable integrated equilibrium.

Proof: See the appendix.

Proposition 3 addresses the case where differences between the public good levels are small enough that demographic preferences dominate in the determination of equilibria. It states that in this range, the stable equilibria are characterized by segregation.

We also note that while difficult to formalize because of the complexity of the boundary bid function relationship presented in Equation 10, it is the case that for all "standard" parameterizations of the model that we have evaluated, the equilibrium with the lower income minority group in the low public good community is stable over a much broader range of public good differences than is the equilibrium with this lower income minority group in the high public good community.

Consider now the opposite extreme, where differences in public goods are very large and effectively drive the sorting behavior, swamping any effect of the demographics. Intuitively, this case will resemble earlier results from Epple et al. (1984) and other related papers with only a public goods component. In particular, individuals will be stratified by income instead of segregated by race.

To operationalize this intuition in our model, assume that, for given levels of $G^{C 2}, D_{r}^{C 1}$, and $D_{r}^{C 2}, B i d_{Y r} \rightarrow Y$ as $G^{C 1} \rightarrow-\infty .^{10}$ Then, at the limit, the boundary income bid functions are equal to the boundary incomes themselves, and both types view Community 2 as more desirable regardless of demographic sorting. By construction (Condition 2), the richest type- $b$ individual is richer than the boundary type- $w$ individual when $P R O P_{w}^{C 1}=1-2 \beta$, and the poorest type- $b$ individual is poorer than the boundary type- $w$ individual when $P R O P_{w}^{C 1}=1$. As a result, the boundary income of type- $b$ individuals crosses the boundary income of type- $w$ individuals exactly once from above. This case has a single equilibrium. The equilibrium is stable

\footnotetext{
${ }^{10}$ This condition essentially says that the public good is a necessity. For example, while there may be great heterogeneity in the marginal values for air quality, nobody can live without some minimum level, below which they would suffocate. While this condition is sufficient for the emergence of a single integrated equilibrium as public good differences increase, it is by no means necessary.
} 
and integrated, with all individuals with income above the population median income locating in Community 2. Proposition 4 formalizes this result.

\section{Proposition 4}

Assume that, for given levels of $G^{C 2}, D_{r}^{C 1}$, and $D_{r}^{C 2}, B i d y^{r} \rightarrow Y$ as $G^{C 1} \rightarrow-\infty$. Then, there exists $\widehat{G}^{C 1}$ such that for all $G^{C 1}<\widehat{G}^{C 1}<G^{C 2}$ there is a single equilibrium that is integrated and stable.

Proof: See the appendix.

That is, when public good differences are sufficiently large, the communities will be integrated by group but stratified by income. In general, how "large" the differences in $G$ must be will depend on the preferences and income distributions.

Even with perfect stratification by income, the high public good community will still have a higher proportion of type- $w$ residents than $C 1$ :

\section{Proposition 5}

Under the conditions of Proposition 4, for sufficiently low $G^{C 1}, P R O P_{w}^{C 2}>P R O P_{w}^{C 1}$. Proof: See the appendix.

The proof of Proposition 5 follows intuitively from Condition (1), first-order stochastic dominance in the income distributions. Essentially, since type- $w$ are richer on average, when there is perfect stratification by income then the richer community also has a higher share of type $w$. In this way, our model captures as a special case the earlier insights from McGuire (1974), who showed how segregation can be driven by group differences in the willingness to pay for public goods. It also speaks to important policy issues. For example, the "environmental justice" movement has shown that minorities are disproportionately exposed to pollution (e.g. Bullard 2000). Thus, our model formalizes the idea that discrimination (at least in pollution patterns) is not necessary to drive observed correlations in the consumption of public goods such as environmental quality. Those correlations may be driven by differences in incomes and sorting on amenities (see also Been 1994).

To summarize the discussion so far, when public good levels in the two communities are relatively similar, all equilibria are segregated. At intermediate differences in public good levels it is difficult to make general statements about equilibria. However, the stable segregated equilibria with all type- $b$ individuals in Community 1 will exist over at least part of this range. Final- 
ly, when differences in public good levels are high there will be a single stable equilibrium with integration.

To further illustrate the implications of Propositions 3 and 4, Figure 3 displays the bid functions for the specification of Figures 1 and 2-fixing the level of $G^{C 2}$ at 1 and varying the level of $G^{C l}$ from 0.25 to 1 . When $G^{C l}=0.25$ the public goods difference is large enough that the outcome resembles the limiting notion of Proposition 4 where the bid functions equal the boundary income functions. When $G^{C l}=0.25$ there is a single stable integrated equilibrium. As $G^{C l}$ increases to 0.5 , the bid functions no longer track the boundary income functions as closely, but there is still a single stable and integrated equilibrium. When $G^{C l}=0.7$, the bid functions no longer cross and the only equilibrium is a stable segregated equilibria with all type- $b$ individuals located in the low public good community. In other words, closing the gap in public goods by improving the public good level in Community 1 causes a change from integrated equilibrium to segregated equilibrium. This stable segregated equilibrium exists in this example for all $1 \geq$ $G^{C l}>0.6$. When $G^{C l}=0.8$, this stable segregated equilibrium continues to exist. In addition, two new equilibria appear, an unstable and a stable integrated equilibrium. Finally, once $G^{C 1}=0.9$, we are in the realm of Proposition 3 with two stable segregated equilibria and one unstable integrated equilibrium. The figure illustrates the results of Propositions 3 and 4. Namely, when public good differences are large, integrated equilibria (with income stratification) are especially salient. When public good differences shrink, segregated equilibria are especially salient.

Figure 4 shows how the equilibria evolve as $G^{C l}$ improves. On the vertical axis it shows levels of $P C T w^{C l}$ that are sustainable as equilibria for different levels of $G^{C l}$, shown on the horizontal axis. The figure continues to illustrate the example shown in Figure 3. The far left of the figure, at very low levels of $G^{C l}$, has a single integrated equilibrium. As $G^{C l}$ improves, $P C T w^{C 1}$ decreases slightly as richer minorities migrate into $C 1$. Then a "tipping point" is reached, with type $w$ "fleeing" $C 1$ to the full extent possible in equilibrium, with the communities becoming completely segregated. Eventually, as $G^{C l}$ improves to the point that it is better than $G^{C 2}$, rich whites begin to move in and the process slowly reverses, until another tipping point is reached and "gentrification" leads to the community becoming all-w. Finally, as the public good gap between $C 1$ and $C 2$ gets "large" we return to income sorting (now with the 
richest households locating in $C 1$.

\subsection{Discussion}

These results speak to at least three important policy and empirical issues in the literature. The first and most central to our application are policy concerns centered on the correlation between low-income and/or minority populations and the levels of local public goods like public school quality, public safety, parks and green space, and environmental quality. The "environmental justice movement," for example, has highlighted such correlations with air pollution and local toxic facilities (see e.g. Been 1994, Bullard 2000). Our model confirms the intuition that such sorting can be the outcome of sorting by income when there are substantial income differentials between groups. More interestingly, racial preferences can strengthen this result, directly and indirectly. First, with the high- $G$ community mostly white, it will be less attractive to minorities. Second, it will also be more expensive simply because of its whiteness. Both factors will tend to drive even fairly rich minorities into the minority district (a theme raised in the law literature by, e.g., Ford 1994).

However, both advocates and analysts have raised concerns that improving public goods in low-quality neighborhoods may drive gentrification (Sieg et al. 2004, Banzhaf and McCormick 2006, NEJAC 2006). While there may well be price effects, our model suggests that it is unlikely that public good improvements will lead to large turnovers in racial or other group compositions. To the contrary, Propositions 3 and 4 together imply that improvements in public goods may increase segregation. ${ }^{11}$ This theoretical result is generally consistent with empirical studies of gentrifying neighborhoods that find little evidence of differential displacement of minority groups. ${ }^{12}$ Perhaps most relevant on this point is the recent empirical finding of McKinnish et al. (2010) that gentrifying neighborhoods are attractive to highly educated black families. Of course, the link is not as direct as one might hope given that this literature remains mute on

\footnotetext{
${ }^{11}$ This of course depends on which of the two stable equilibria obtain. However, a move to the stable segregated equilibria with all type- $b$ individuals in the high public good community would require a much larger shift in populations than is required for a move to the stable segregated equilibria with all type- $b$ individuals in the low public good community.

${ }^{12}$ See for instance Vigdor (2002), Freeman and Braconi (2004), Freeman (2005), and McKinnish et al. (2010).
} 
the underlying drivers of the gentrification that it seeks to study.

A second application of our model is to the recent revival of interest in "tipping models" of racial segregation (e.g. Card, Mas, and Rothstein, 2008, Pancs and Vriend, 2007). Although Schelling $(1969,1971)$ noted the link between public goods and demographic sorting in his early work, the role of public goods has generally been under appreciated in models of segregation. For example, Card, Mas, and Rothstein (2008) recently have conducted a study of "tipping" behavior in US Cities. They identify tipping points using tract-level data, looking for break points in the change in the white population as a flexible function of the baseline minority composition of the tract. They assume tipping points are identical for all tracts within a metropolitan area. However, our model suggests this is unlikely to be the case. When two tracts have large differences in locational amenities, integration is supportable even with large proportions of minorities. Conversely, when two tracts have small differences in amenities, only low levels of integration can be supported before tipping occurs.

Figure 5 illustrates this point. The first panel in the figure corresponds to the last panel in Figure 3 (i.e., the case where $G_{l}=G_{2}=1$ ), but with the $x$-axis re-normalized to represent the proportion of a community's residents who are type- $b$ rather than type- $w$. In this symmetric case, both communities have a tipping point where the proportion of type- $b$ equals 0.25 . "White flight" occurs where $P R O P_{b}$ exceeds 0.25 . The second and third panels in Figure 5 correspond to the fourth panel in Figure 3 (i.e., the case where $G_{1}=0.8$ and $G_{2}=1$ ). Panel two depicts Community 1 . With these values of $G, C 1$ experiences white flight whenever $P R O P_{b}$ exceeds $0.21{ }^{13}$ Comparing the first and second panels, we are essentially decreasing $G$ from 1 to 0.8 while holding $G$ in the relevant substitute community constant at 1 . This is sufficient to lower the tipping point from a proportion of type- $b$ of 0.25 to 0.21 .

The third panel of Figure 5 depicts Community 2 in the same "city" as the second panel. Here, tipping occurs whenever $P R O P_{b}$ exceeds 0.29. Comparing the first and third panels of this figure, we hold constant the value of the public goods in Community 2 at $G=1$. But in panel 1

\footnotetext{
${ }^{13}$ There is also a stable integrated equilibrium where $P R O P_{b}=0.11$, but as this is a stable equilibrium increases in $P R O P_{b}$ above this level but below 0.21 do not trigger tipping. A tipping point is not reached until $P R O P_{b}$ exceeds 0.21 in this community.
} 
the substitute community has $G=1$ while in panel 3 the substitute community has $G=0.8$. This is sufficient to move the tipping point from a proportion of type- $b$ of 0.25 to 0.29 . Thus, not only does the level of public goods in a community determine the tipping point, but so too does the level of the public goods in the relevant substitute community.

This sensitivity of the tipping point to public goods may be one reason more noise appears in Card, Mas and Rothstein's predictions about demographic changes around their estimated tipping point (see their Figure 4). Our model suggests more precise estimates of tipping points could be obtained by adjusting for differences in public goods using multiple regression or other methods.

Third, our results may help explain recent empirical puzzles about the demographic effects of environmental cleanup. As noted above, the environmental justice literature shows that the presence of minority households is correlated with undesirable facilities like hazardous waste sites. But recently, using difference-in-difference methods, Cameron and McConnaha (2006), Greenstone and Gallagher (2008), and Vigdor (2009) have found that improvements to such sites do not appear to reduce these correlations. They suggest this may be because of long-lasting "stigma" of the sites or the ineffectualness of cleanup. Our results suggest another explanation: the reduced form relationship may change after a cleanup, so that the correlation between pollution and race becomes even stronger, not weaker as supposed in the literature. To illustrate this point, consider the difference-in-difference relationships that come out of the previous example. Figure 6 plots the relationship between $G^{j}$ and $P R O P_{b}^{j}$ for our two communities, with $G^{C 2}=1$ and $G^{C l}$ taking on each of the values used in Figure $3(0.25$ to 0.9$)$. The lines in the bottom panel shows the cross-sectional relationships for each value of $G^{C l}$. The lines illustrating the crosssectional relationships become successively steeper as $G^{C l}$ improves, consistent with our finding that racial correlations strengthen with improving $G^{C l}$, as sorting on race becomes more salient. The top panel shows difference-in-differences for each successive improvement in $G^{C l}$. Together, the two panels clearly show that while the cross-sectional differences have the expected negative slope, the difference-in-differences have the opposite slope.

One way to think about this problem is in terms of a mis-specification of the standard difference-in-differences regression. Our model suggests that the correlation between race and 
public goods increases as the low public good community sees increases in its public good level. Consider the reduced form relationships between minority compositions and pollution in community $j$ in two time periods ( 0 and 1$)$ :

$$
\begin{aligned}
& \text { PCTMINORITY }_{j 0}=t_{0}+\alpha_{j}+\beta_{0} \text { POLLUTION }_{j 0}+\epsilon_{j 0} \\
& \text { PCTMINORITY }_{j 1}=t_{1}+\alpha_{j}+\beta_{1} \text { POLLUTION }_{j 1}+\epsilon_{j 1}
\end{aligned}
$$

with time-specific intercepts $t$ in each of the two time periods, time-invariant fixed effects for each community, $\alpha_{j}$, and time-specific pollution effects $\beta_{1}>\beta_{0}>0$. First differencing the equations leads to:

$$
\triangle P C T M I N O R I T Y_{j}=\Delta t+\beta_{1} \Delta \text { POLLUTION }_{j}+\left(\beta_{1}-\beta_{0}\right) \text { POLLUTION }_{j 0}+\Delta \epsilon_{j}
$$

If POLLUTION ${ }_{j 0}$ is omitted from equation (13), the estimate of $\beta_{1}$ will be biased downward when $\triangle$ POLLUTION and POLLUTION are negatively correlated (i.e. if the dirtiest areas are being cleaned up). In this case, the problem may simply be one of omitted variables. Including baseline pollution levels is suggested as a control. Although this kind of Oaxaca procedure is common in the labor literature, the literature on local public goods has tended to ignore its importance. Our model shows why it is important to take account of the changes in the reduced form relationships.

\section{Empirical Example}

In essence, our model predicts that an exogenous improvement in public goods that closes the public goods gap across neighborhoods will change locational equilibria in such a way as to put more emphasis on sorting by race. ${ }^{14}$ As discussed above, the model's theoretical predictions are generally consistent with recent empirical results on gentrification and the impacts of environmental remediation. However, these empirical results are rather weak evidence as to the model's

\footnotetext{
${ }^{14}$ It might seem equally true that it should put less emphasis on sorting by income. However, this is not necessarily so. The reason can be seen in the logic of Figure 6. As $G^{C l}$ rises and $P C T w^{C l}$ falls, both effects lead to a higher absolute value of the slope in the cross-sectional relationship between race and $G$. In contrast, as $G^{C l}$ rises and mean income rises in $C 1$, there are two offsetting effects on the cross-sectional relationship between income and $G$.
} 
empirical relevance. Unfortunately, to our knowledge, there is no extant work that bears directly on this question. As an initial attempt to fill this gap, we consider the demographic shifts associated with large reductions in localized toxic air emissions that occurred in California between 1990 and 2000, using a data set previously assembled by Banzhaf and Walsh (2008).

At the core of the data are 25,166 "communities" defined by a set of tangent half-mile diameter circles evenly distributed across the urbanized portion of California. This approach has the virtue of establishing equally sized communities with randomly drawn boundaries, in contrast to political and census boundaries which may be endogenous. These neighborhoods are matched to the presence of large industrial emitters of air pollution and their emissions levels, as recorded in the Toxic Release Inventory (TRI), in each year from 1990 to 2000. TRI releases are a common measure of pollution in the literature on the relationship between environmental quality and demographic composition. ${ }^{15}$ Firms handling more than 10,000 pounds each year of certain hazardous chemicals have been required to report these emissions since 1987. This censoring at the reporting threshold gives rise to a kind of errors-in variables problem. As in the usual case, this is likely to have a "conservative" effect on our results, biasing them to zero, as some exposed communities are included in the control group. See de Marchi and Hamilton (2006) for further discussion of the data. We use a three-year lagged average of the toxicityweighted emissions of all chemicals reported since 1988, looking at the change from 1988-90 to $1998-2000 .^{16}$

Emissions from each plant are assumed to disperse uniformly over a half-mile buffer zone, and are allocated to each residential community accordingly. The data are also matched to 1990 and 2000 block-level census data on the total populations of each racial group. These block-level data are aggregated to the circle-communities assuming uniform distributions within each block. See Banzhaf and Walsh (2008) for additional details including summary statistics.

Ten percent of our communities were exposed to at least some TRI emissions in the base-

\footnotetext{
${ }^{15}$ E.g., Arora and Cason (1996), Brooks and Sethi (1997), Kriesel et al. (1996), Morello-Frosch et al. (2001), Rinquist (1997), Sadd et al. (1999).

${ }^{16}$ The list of reporting chemicals greatly expanded in 1994. To maintain a consistent comparison of TRI emissions over time, we have limited the data to the common set of chemicals used since 1988.
} 
line period (1988-1990), with 4 percent of our communities (or approximately $40 \%$ of those exposed in 1988-1990) losing their exposure by 1998-2000. Figure 7 shows the link between baseline TRI exposure and the 10-year change in emissions. The figure clearly demonstrates that the largest pollution reductions occurred in the communities with the highest baseline emissions. Thus, these improvements are consistent with the "large" improvements in low-public good communities discussed above.

Using these data, we test for changes in the structural relationships between race and pollution over time. In particular, we estimate

$$
\text { PctMinority }{ }_{j}^{t}=\theta_{0}^{t}+\mu_{E}^{t} E_{j}^{t}+\theta_{I}^{t} I_{j}^{t}+\theta_{L} L_{j}+u_{j}^{t}
$$

where $E_{j}^{t}$ is an indicator for whether community $j$ was "exposed" to TRI pollution (i.e. was within a half-mile of at least one such facility) in year $t$ and $I$ is the continuous level of air emissions from nearby facilities allocated to community $j$. The variable $E$ captures the extensive margin and any non-air pollution related disamenity of the polluting facilities (visual, noise, smell), while $I$ captures the intensive margin, namely emissions weighted by EPA's toxicity index.

A key challenge to identifying changes predicted by the model is the likely presence of other, confounding location-specific public goods. Our approach to controlling for unobserved spatial amenities is to employ in $L_{j}$ successively more stringent time-invariant spatial variables, including controls for latitude and distance from the coast, school district dummies, and zip code dummies. These effects should capture unobserved public goods that vary on a spatial scale that exceeds that of the pollution impacts from TRI facilities. School district fixed effects have the advantage of mapping directly into an important but difficult-to-measure local public good, and zip code fixed effects control for locational amenities that vary on spatial scale much smaller than that of a school district.

Table 1 displays the results. It shows the estimated effects, in each year, of a typical level 
of exposure in 1990 (for exposed communities). ${ }^{17}$ That is, for each year, it shows

$$
\theta_{I}^{t}\left(\frac{1}{\sum_{j} 1\left(I_{j}^{1990}>0\right)} \sum_{j \mid} I_{j}^{1990}\right)+\theta_{E}^{t} .
$$

The table clearly shows that as the public goods gap shrinks from 1990 to 2000, sorting on race increased-precisely the predictions in the model. As the time-invariant locational controls get more local, the estimated levels of the cross-sectional sorting parameter shrink, perhaps because of unobservables or perhaps simply because less variation remains for estimating the model. But in all cases, the estimated change in the relationship is consistently around 3 percentage points and highly significant. That is, the effect of a "typical" polluting plant was associated with more minorities in both years, but in 2000 the typical plant was associated with an increase in nearby minorities 3 percentage points more than was the same sized plant in 1990.

Moreover, these results are robust to a number of alternative specifications of the model. In particular, we estimated the model on only the extensive margin of proximity to a polluting facility as well as only the intensive margin of logged emissions. The results are qualitatively similar for these variants of the model. We also estimated the model separately on the eight metropolitan statistical areas in California with populations above 1 million. Again, the cityspecific results are qualitatively similar to the pooled results, though naturally somewhat less precise. ${ }^{18}$ Finally, the effects are qualitatively similar if we consider the effect of an average size plant in 2000 rather than 1990.

\section{Conclusions}

Our model suggests that any analysis of the distribution of spatially delineated public goods across demographic groups must account for endogenous sorting on those demographics, while at the same time studies of spatial patterns in demographics must account for public goods. That

\footnotetext{
${ }^{17}$ Similar results are obtained by using the average of 2000 emissions as an alternative normalization.

${ }^{18}$ In particular, for all three specifications of the spatial controls, the effect of the normalized level of pollution was greater in 2000 than in 1990 for six of the eight metropolitan statistical areas, with the difference being statistically significant in four or five of these cities, depending on the model. The estimated effect of pollution was actually smaller in 2000 than in 1990 for two of the eight cities, but the difference is not statistically significant. Detailed results are available from the authors.
} 
is, sorting models in the tradition of Tiebout (1956) and tipping models in the tradition of Schelling (1969) are fundamentally connected. We show that when sorting includes demographics, changes in public goods can lead to counter-intuitive results. In particular, improving public good levels in disadvantaged communities can actually increase segregation.

Schelling's $(1969,1971)$ original insight into these issues was that complete segregation can result even with ubiquitous tastes for some positive level of integration, a result recently extended by Pancs and Vriend (2007). Consequently, modest changes in preferences are unlikely to reduce segregation. More recently, Bayer et al. (2005) and Sethi and Somanathan (2004) find that increasing the number of high socio-economic status minorities in a city actually can increase segregation. They find that such people-based policies have this effect because richer minorities now have enough mass to form their own high-income communities.

Our results suggest that place-based policies pose the same dilemma, but for a different reason: group-based sorting becomes more salient when there is less reason to sort on the exogenous public good. Taken in the context of the existing literature, our results contribute to a theme that now appears to be growing by accretion. Apparently, neither changes in tastes nor changes in income distributions nor changes in the spatial distribution of public goods are likely to reduce the level of segregation in a society. Little wonder, then, that segregation has been such a universal part of human history. 


\section{References}

Arora, Seema, and Timothy N. Cason. 1999. "Do Community Characteristics Influence Environmental Outcomes? Evidence from the Toxics Release Inventory." Southern Economic Journal 65(4): 691-716.

Ash, Michael, and T. Robert Fetter. 2004. "Who Lives on the Wrong Side of the Environmental Tracks? Evidence from the EPA's Risk-Screening Environmental Indicators Model." Social Science Quarterly 85: 441-62

Banzhaf, H. Spencer, and Eleanor McCormick. 2006. "Moving Beyond Cleanup: Identifying the Crucibles of Environmental Gentrification." National Center for Environmental Economics Working Paper 07-02. http://yosemite.epa.gov/EE/epa/eed.nsf/WPNumberNew/200702? OpenDocument.

Banzhaf, H. Spencer, and Randall P. Walsh. 2008. "Do People Vote with Their Feet? An Empirical Test of Tiebout's Mechanism." American Economic Review 98: 843-63.

Bayer, Patrick, Hanming Fang, and Robert McMillan. 2005. "Separate When Equal? Racial Inequality and Residential Segregation." NBER Working Paper 11507. http://www.nber.org/papers/w11507.

Becker, Gary S., and Kevin M. Murphy. 2000. Social Economics: Market Behavior in a Social Environment, Chapter 5. Cambridge, MA: Belknap Press.

Been, Vicki. 1994. "Locally Undesirable Land Uses in Minority Neighborhoods: Disproportionate Siting or Market Dynamics?" Yale Law Journal 103: 1383-1422.

Brooks and Sethi. 1997. "The Distribution of Pollution: Community Characteristics and Exposure to Air Toxics." Journal of Environmental Economics and Management 32: 233-50.

Bullard, Robert. 2000. Dumping in Dixie, $3^{\text {rd }}$ ed. Westview Press.

Cameron, Trudy Ann, and Ian McConnaha. 2006. "Evidence of Environmental Migration." Land Economics 82: 273-290.

Card, David, Alexandre Mas, and Jesse Rothstein. 2007. "Tipping and the Dynamics of Segregation." Quarterly Journal of Economics, forthcoming.

Cutler, David M., Edward L. Glaeser, and Jacob L. Vigdor. 1999. "The Rise and Decline of the American Ghetto." Journal of Political Economy 107(3): 455-506.

de Marchi, Scott, and James T. Hamilton. 2006. "Assessing the Accuracy of Self-Reported Data: An Evaluation of the Toxics Release Inventory." Journal of Risk and Uncertainty 32: 5776.

Debreu, Gerard. 1970. "Economies with a Finite Set of Equilibria." Econometrica 38: 387-92.

Epple, Dennis, Radu Filimon, and Thomas Romer. 1984. "Equilibrium among Local Jurisdictions: Toward an Integrated Approach of Voting and Residential Choice." Journal of Public Economics 24: 281-308.

Farley, Reynolds, Howard Schuman, S. Bianchi, Diane Colasanto, and S. Hatchett. 1978. "Choc- 
olate City, Vanilla Suburbs: Will the Trend toward Racially Separate Communities Continue?" Social Science Research 7: 319-344.

Farley, Reynolds, and Maria Krysan. 2002. "The Residential Preferences of Blacks: Do They Explain Persistent Segregation?" Social Forces, 80: 937-80.

Freeman, L. 2005. "Displacement or Succession? Residential Mobility in Gentrifying Neighborhoods" Urban Affairs Review 40(4): 463-491.

Freeman, L. and F. Braconi. 2004. "Gentrification and Displacement in New York City" Journal of the American Planning Association, 70(1): 39-52.

Ford, Richard Thompson. 1994. "The Boundaries of Race: Political Geography in Legal Analysis." Harvard Law Review 107: 1841-1921.

Glaeser, Edward L., and Jose A. Scheinkman. 2003. "Non-Market Interactions." In Advances in Economics and Econometrics: Theory and Applications, $8^{\text {th }}$ World Congress, Vol. 1, ed. by M. Dewatripont, L.P. Hansen, and S. Turnovosky. Cambridge: Cambridge University Press, pp. 339-69.

Greenstone, Michael, and Justin Gallagher. 2008. "Does Hazardous Waste Matter? Evidence from the Housing Market and the Superfund Program." Quarterly Journal of Economics 123: 951-1003.

Hoff, Karla, and Arijit Sen. 2005. "Homeownership, Community Interactions, and Segregation." American Economic Review 95: 1167-89.

Kiel, Katherine A., and Jeffrey E. Zabel. 1996. "House Price Differentials in US Cities: Household and Neighborhood Racial Effects." Journal of Housing Economics 5: 14365 .

Kriesel, Warren, Terence J. Centner, and Andrew G. Keller. 1996. "Neighborhood Exposure to Toxic Releases: Are there Racial Inequities?" Growth and Change 27: 479-99.

McGuire, Martin. 1974. "Group Segregation and Optimal Jurisdictions." Journal of Political Economy 82: 112-32.

McKinnish, Terra, Randall Walsh, and T. Kirk White. 2010. "Who Gentrifies Low-Income Neighborhoods?" Journal of Urban Economics, 67(2): 180-193.

Morello-Frosch, Rachel, Manuel Pastor, and James Sadd. 2001. "Environmental Justice and Southern California's 'Riskscape': The Distribution of Air Toxics Exposures and Health Risks Among Diverse Communities." Urban Affairs Review 36(4): 551-578.

National Environmental Justice Advisory Council (NEJAC). 2006. Unintended Impacts of Redevelopment and Revitalization Efforts in Five Environmental Justice Communities. Report, August.

Pancs, Romans, and Nicolaas J. Vriend. 2007. "Schellings' Spatial Proximity Model of Segregation Revisited." Journal of Public Economics 91: 1-24.

Rinquist, Evan J. 1997. "Equity and Distribution of Environmental Risk: The Case of TRI Facilities." Social Science Quarterly 78: 811-829. 
Sadd, James L., Manuel Pastor, J. Thomas Boer, and Lori D. Snyder. 1999. "'Every Breath You Take...:' The Demographics of Toxic Air Releases in Southern California." Economic Development Quarterly 13(2): 107-123.

Schelling, Thomas C. 1969. "Models of Segregation." American Economic Review papers and proceedings 59: 488-93.

Schelling, Thomas C. 1971. "Dynamic Models of Segregation." Journal of Mathematical Sociology 1: 143-86.

Sethi, Rajiv, and Rohini Somanathan. 2004. "Inequity and Segregation." Journal of Political Economy 112: 1296-1321.

Sieg, Holger, V. Kerry Smith, H. Spencer Banzhaf, and Randy Walsh. 2004. "Estimating the General Equilibrium Benefits of Large Changes in Spatially Delineated Public Goods." International Economic Review 45(4): 1047-1077.

Tiebout, Charles. 1956. "A Pure Theory of Local Expenditures." Journal of Political Economy 64: 416-424.

Vigdor, Jacob L. 2202. “Does Gentrification Harm the Poor?” Brookings-Wharton Papers on Urban Affairs: 133-173.

Vigdor, Jacob L. 2009. "Does Environmental Remediation Benefit the Poor?" Paper presented at the Lone Mt. Forum on "The Political Economy of Environmental Justice," Big Sky, MT, Oct 2008. Revised June 2009. 
Figure 1: Community Sorting and Bid Functions $\left(G^{C 1}=G^{C 2}=1\right)$.

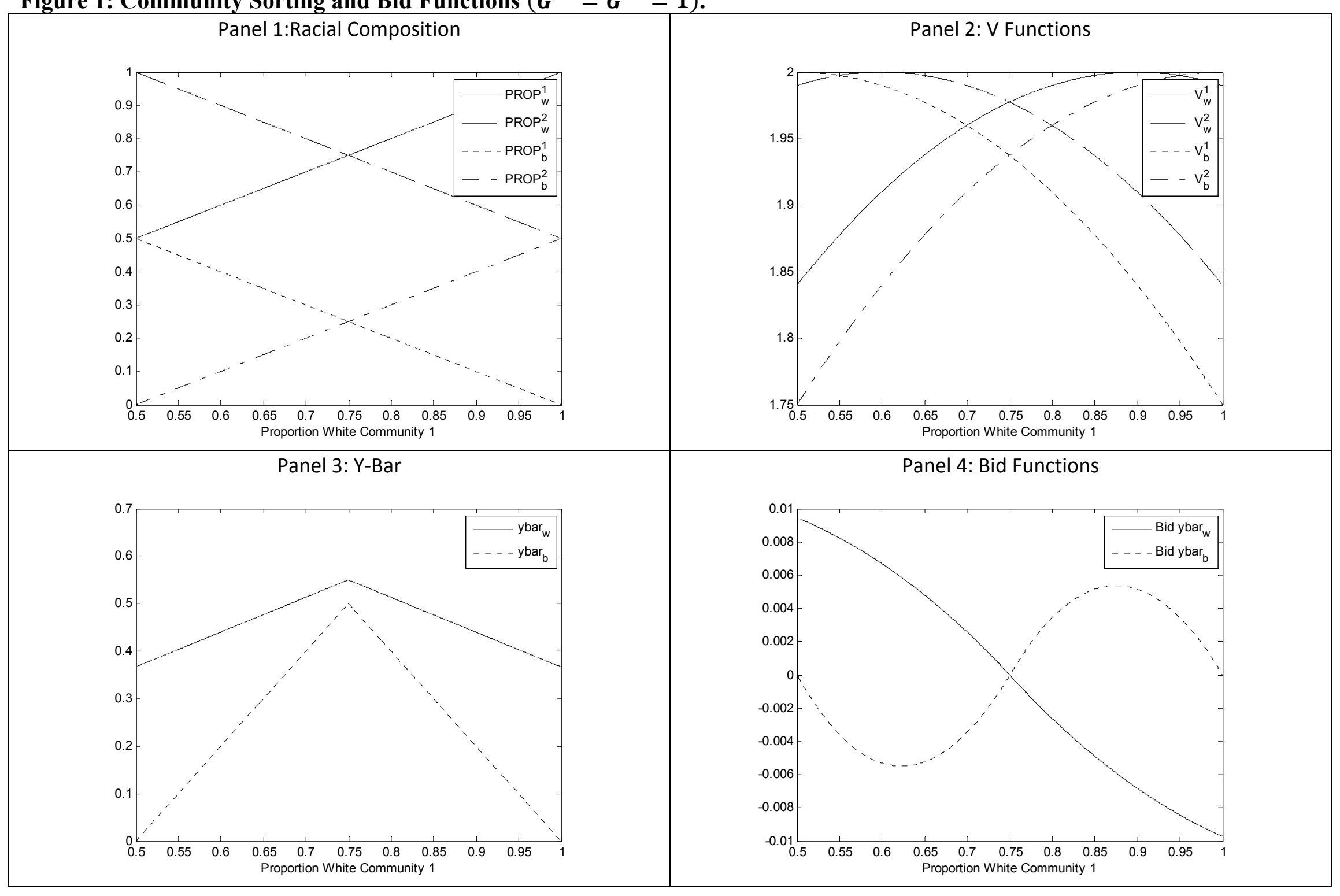


Figure 2: Community Sorting and Bid Functions $\left(G^{C 1}=.9, G^{C 2}=1\right)$.

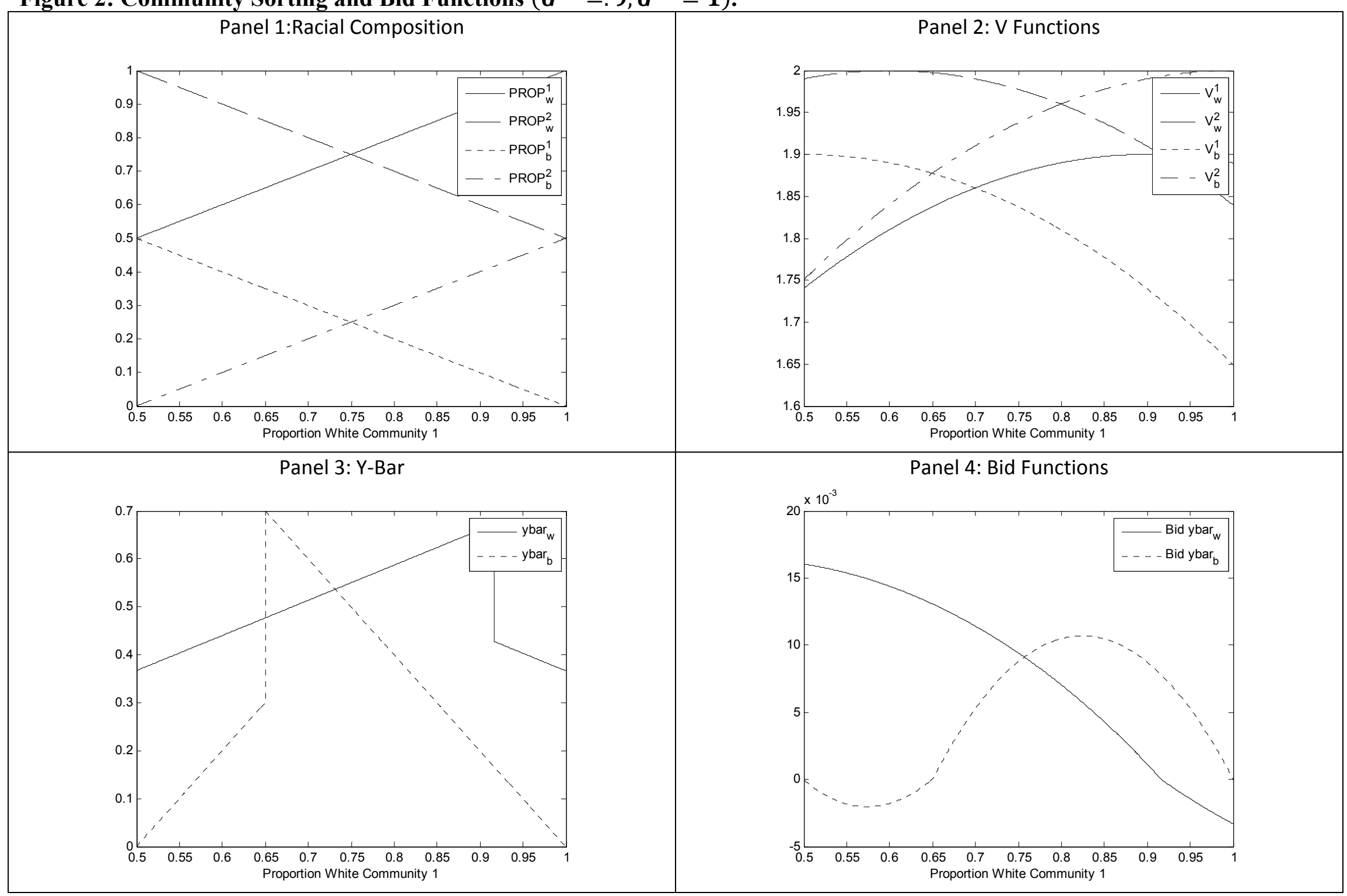


Figure 3: Impact of Changes in $G^{C 1}$ on Bid Functions.

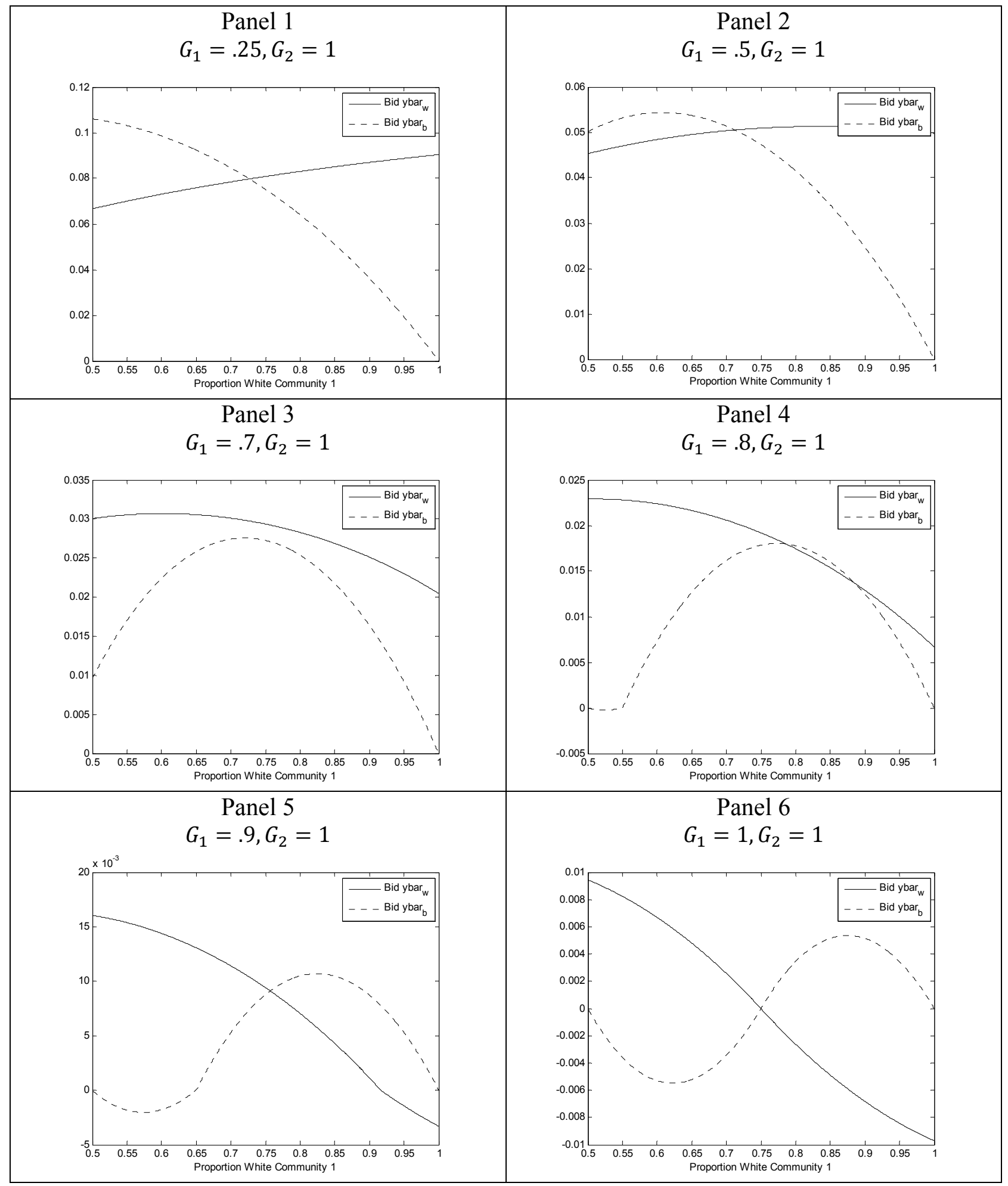


Figure 4: Evolution of Equilibria as $G^{C 1}$ Improves.

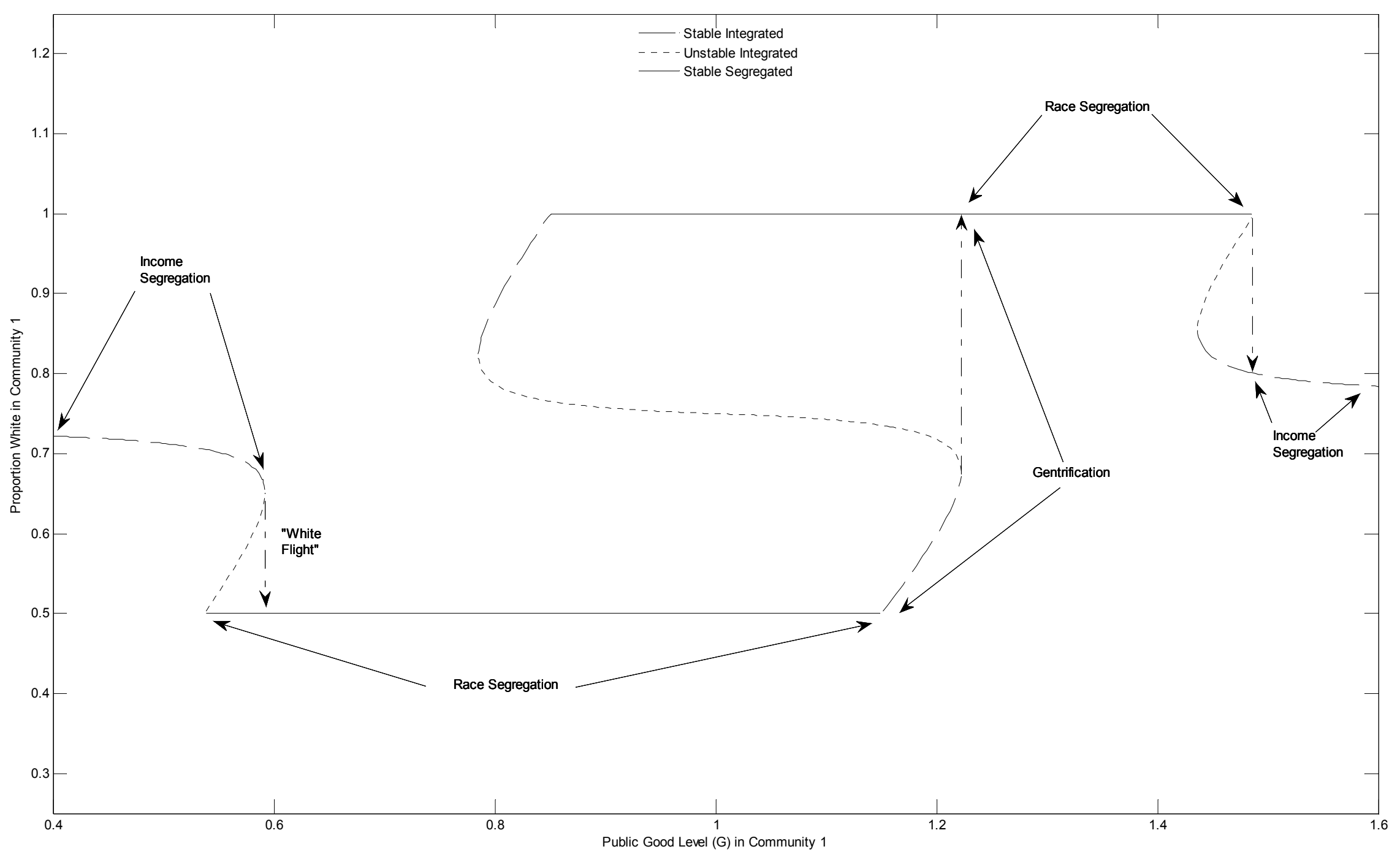


Figure 5. Sensitivity of Neighborhood Tipping Points to Public Goods Levels.

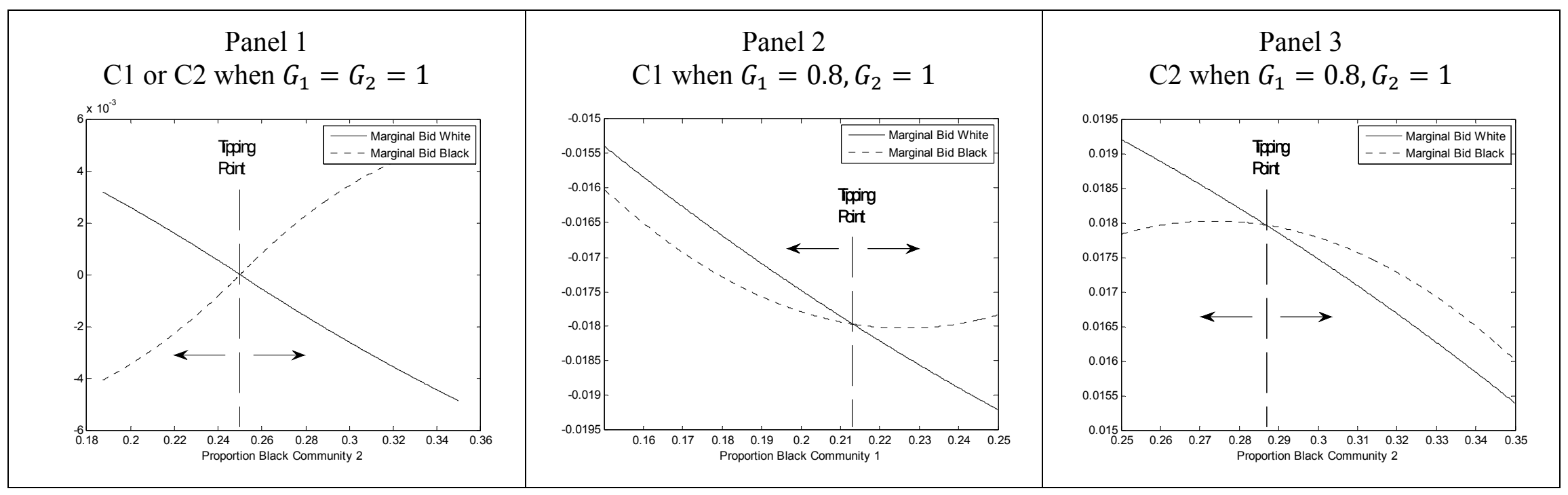


Figure 6: Difference in Difference and Cross Sectional Relationships.

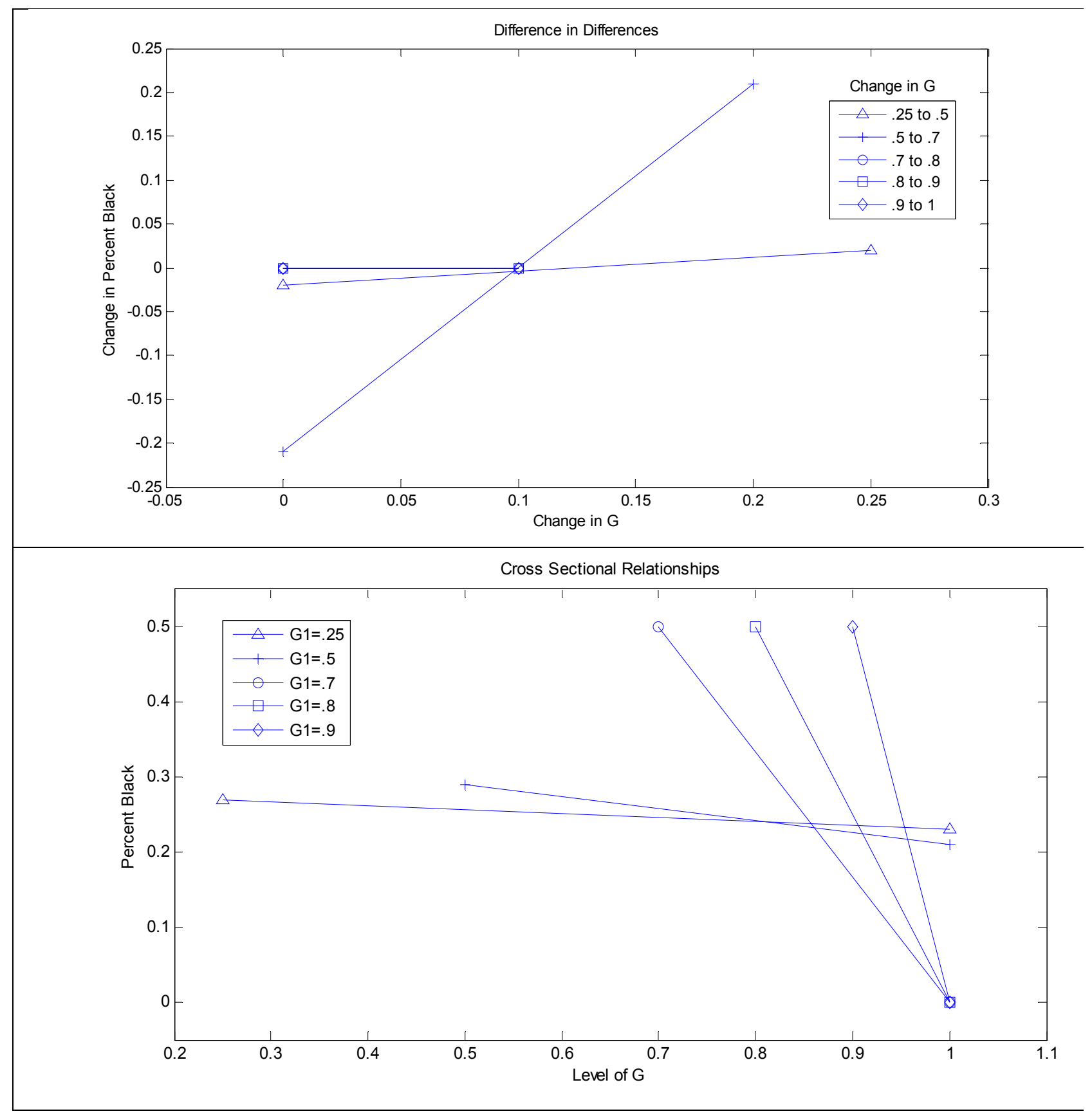


Figure 7. Improvements in TRI Emissions, 1990-2000 (3-year average).

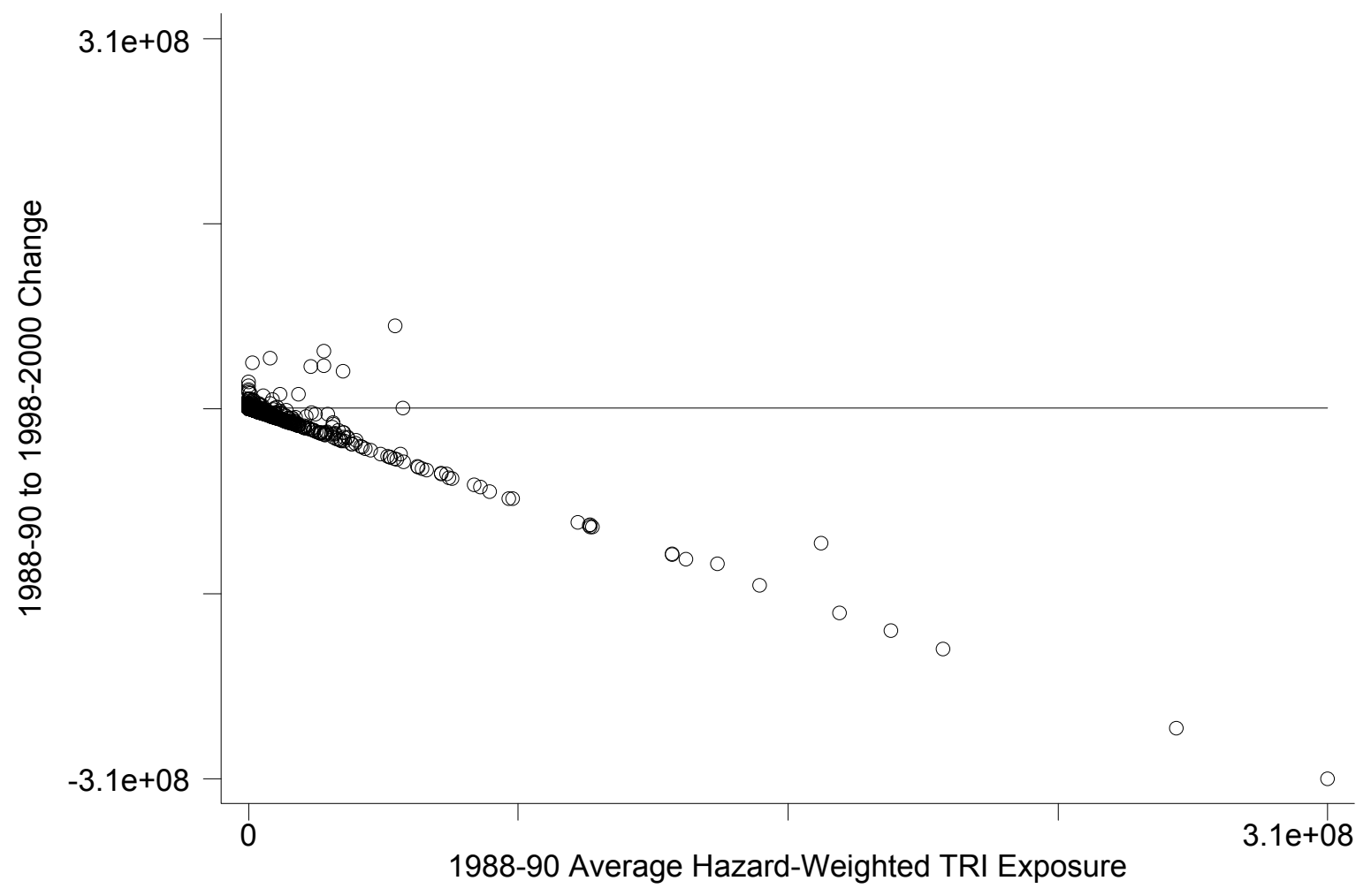


Table 1. Estimated Effect of Average TRI Exposure in 1990 and 2000 (and Difference) on Percent Minority.

\begin{tabular}{lcccc}
\hline \hline Spatial controls L & Effect in 1990 & Effect in 2000 & Difference & $\mathbf{R}^{2}$ \\
\hline Latitude, Dist Coast & $21.3^{* * *}$ & $24.3^{* * *}$ & $3.0^{* * *}$ & 0.10 \\
School Dist dummies & $(0.6)$ & $(0.8)$ & $(1.0)$ & \\
& $11.7^{* * *}$ & $14.3^{* * *}$ & $2.6^{* * *}$ & 0.45 \\
Zip Code dummies & $(0.5)$ & $(0.7)$ & $(0.8)$ & \\
& $4.2^{* * *}$ & $7.0^{* * *}$ & $2.8^{* * *}$ & 0.69 \\
\hline \hline
\end{tabular}

Estimates are for the effect of $\theta_{I}^{t}\left(\frac{1}{\sum_{j} 1\left(I_{j}^{1990}>0\right)} \sum_{j} I_{j}^{1990}\right)+\theta_{E}^{t}$. That is, they are the effect in year $t$ of the typical exposure experienced in 1990 (if any) compared to no exposure. The effect accounts for the extensive margin of such "typical exposure" as well as the intensive margin of emission levels.

Robust standard errors are in parentheses.

$* * *$ Significant at $1 \%$ level, $* * 5 \%, * 10 \%$. 


\section{Appendix.}

\section{Proof of Proposition 2}

We begin by noting that when public good levels are equal:

(a) $\operatorname{Bid}_{\bar{Y}_{b}}<\operatorname{Bid}_{\bar{Y}_{w}}$ when $P C T w^{C l}<1-\beta$,

(b) $\quad \operatorname{Bid}_{\bar{Y}_{b}}>\operatorname{Bid}_{\bar{Y}_{w}}$ when $P C T w^{C l}>1-\beta$, and

(c) $\quad \operatorname{Bid}_{\bar{Y}_{b}}=\operatorname{Bid}_{\bar{Y}_{w}}=0$ when $P C T w^{C l}=1-\beta$.

(a) is true because $D_{r}^{j}$ is highest in the community with more of type $j$. With $G^{C 1}=G^{C 2}$, it follows that $V_{r}^{j}$ is also higher in that community. (b) follows by the symmetric logic. (c) also follows by similar logic: in this case, $D_{r}{ }^{C 1}=D_{r}{ }^{C 2}$ so $V^{C 1}=V^{C 2}$. Observation 4 shows that (a) and (b) are associated with segregated equilibria. As already noted, all segregated equilibria are stable. Observation 5 shows that (c) is associated with an integrated equilibrium. However, this equilibrium is unstable because as soon as a single type- $w$ individual in $C 1$ switches with a type- $b$ individual in $C 2$, then $P C T w^{C l}<1-\beta$ and we are in case (a). Likewise, if a type- $w$ individual in $C 2$ switches with a type- $b$ individual in $C 1$, we are in case (b).

\section{Proof of Proposition 3}

The proposition follows directly from Proposition 2 together with the continuity of the boundary income bid functions and the implicit function theorem. It states that the single unstable integrated equilibrium and the segregated equilibrium with all type- $b$ individuals in $C 2$ that are present when public goods are equal continues to hold and are the only possible equilibria for at least small perturbations in the $G$ 's around this point.

\section{Proof of Proposition 4.}

We prove this proposition in four steps.

Part (i).

We begin by re-writing Equation 4 as follows:

$$
\frac{d B i d_{\bar{Y}_{r}}}{d P C T w^{C 1}}=\frac{d \bar{Y}_{r}}{d P C T w^{C 1}}+\left[\left(U_{V}^{C 2} V_{D}^{C 2} \frac{d D_{r}^{C 2}}{d P C T w^{C 1}}-U_{V}^{C 1} V_{D}^{1 C 1} \frac{d D_{r}^{C 1}}{d P C T w^{C 1}}\right)-U_{x}^{C 1}\right] \frac{1}{U_{x}^{C 2}}
$$


By assumption, $B i d_{Y} \rightarrow Y$ as $G^{C 1} \rightarrow-\infty$. Thus, by the Inada conditions $U_{x}^{C 2} \rightarrow \infty$. Therefore, for sufficiently low $G^{C l}$, the entire term in brackets $\rightarrow 0$ and we can focus on the first term $\frac{d \bar{Y}_{r}}{d P C T w^{C 1}}$.

As shown in the text,

$$
\begin{gathered}
\frac{d \bar{Y}_{b}}{d P C T w^{C 1}}=-\frac{0.5}{\beta f_{b}\left(\bar{Y}_{b}\right)}<0 \\
\frac{d \bar{Y}_{w}}{d P C T w^{C 1}}=\frac{0.5}{(1-\beta) f_{w}\left(\bar{Y}_{w}\right)}>0
\end{gathered}
$$

whenever $V_{r}^{C 1}>V_{r}^{C 2}$. Therefore,

$$
\frac{d \operatorname{Bid}_{\bar{Y}_{b}}}{d P C T w^{C 1}}<0
$$

and

$$
\frac{d \operatorname{Bid}_{\bar{Y}_{w}}}{d P C T w^{C 1}}>0 .
$$

In other words, the boundary income bid function is monotonically increasing in $P C T w^{C l}$ for type $w$ and monotonically decreasing for type $b$.

Part (ii).

Next, note that at $P C T w^{C l}=1-2 \beta, \bar{Y}_{b}=Y_{b}^{M a x}$ and $\bar{Y}_{w}=F_{w}^{-1}\left(\frac{0.5-\beta}{1-\beta}\right)<F_{w}^{-1}(1-2 \beta)$ given $\beta<0.5$. Again, since $\operatorname{Bid}_{y} \rightarrow y$, it follows that $\operatorname{Bid}_{\bar{Y}_{b}}=Y_{b}^{M a x}$ and $\operatorname{Bid}_{\bar{Y}_{w}}=F_{w}^{-1}(1-2 \beta)$. Using Equation (1), we then have $\operatorname{Bid}_{\bar{Y}_{b}}>\operatorname{Bid}_{\bar{Y}_{W}}$. Note that by Observation 4, this cannot be an equilibrium.

\section{Part (iii)}

Similarly, note that at $P C T w^{C l}=1, \bar{Y}_{b}=Y_{b}^{M i n}=0$ and $\bar{Y}_{w}=F_{w}^{-1}\left(\frac{0.5}{1-\beta}\right)>0$. Thus $\operatorname{Bid}_{\bar{Y}_{w}}>\operatorname{Bid}_{\bar{Y}_{b}}=0$. Again, by Observation 4, this cannot be an equilibrium.

Part (iv)

We now combine parts (i) to (iii). By part (ii), we have that at $P C T w^{C l}=1-2 \beta, B i d_{\bar{Y}_{b}}>B i d_{\bar{Y}_{w}}$. By part (i), we know $B i d_{\bar{Y}_{b}}$ is monotonically decreasing in $P C T w^{C l}$ and $B i d_{\bar{Y}_{W}}$ is monotonically increasing. By part (iii) we have that at $P C T w^{C l}=1, B i d_{\bar{Y}_{b}}<B i d_{\bar{Y}_{w}}$. Therefore, the two boun- 
dary income bid functions cross once, with $B i d_{\bar{Y}_{b}}$ crossing $B i d_{\bar{Y}_{b}}$ from above. This is a stable integrated equilibrium. Moreover, as noted above the segregated equilibria are ruled out by Observation 4.

Therefore, a single equilibrium exists, it is integrated, and it is stable.

\section{Proof of Proposition 5.}

By Observation (5), in an integrated equilibrium $\operatorname{Bid}_{\bar{Y}_{w}}=\operatorname{Bid}_{\bar{Y}_{b}}$. Since $\operatorname{Bid}_{Y r} \rightarrow Y$ as $G^{C l} \rightarrow-\infty$, it follows that $\bar{Y}_{w}=\bar{Y}_{b}=\bar{Y}$. By first order stochastic dominance, $F\left(\bar{Y}_{b}\right) / F\left(\bar{Y}_{w}\right) \geq 1$.

Therefore,

$$
\frac{F\left(\bar{Y}_{b}\right)}{F\left(\bar{Y}_{w}\right)} \geq \frac{1-F\left(\bar{Y}_{b}\right)}{1-F\left(\bar{Y}_{w}\right)}
$$

and

$$
\frac{\beta F\left(\bar{Y}_{b}\right)}{(1-\beta) F\left(\bar{Y}_{w}\right)} \geq \frac{\beta\left(1-F\left(\bar{Y}_{b}\right)\right)}{(1-\beta)\left(1-F\left(\bar{Y}_{w}\right)\right)}
$$

This shows that the ratio of type $b$ to type $w$ is higher in $C 1$ than $C 2$. Adding 1 written as

$$
\frac{(1-\beta)\left(1-F\left(\bar{Y}_{w}\right)\right)}{(1-\beta)\left(1-F\left(\bar{Y}_{w}\right)\right)}
$$

to both sides of the equation and inverting both sides leads to

$$
\frac{(1-\beta) F\left(\bar{Y}_{w}\right)}{(1-\beta) F\left(\bar{Y}_{w}\right)+\beta F\left(\bar{Y}_{b}\right)}<\frac{(1-\beta)\left(1-F\left(\bar{Y}_{w}\right)\right)}{(1-\beta)\left(1-F\left(\bar{Y}_{w}\right)\right)+\beta\left(1-F\left(\bar{Y}_{b}\right)\right)}
$$

which is the desired result. 